\title{
Impact of oceanic processes on the carbon cycle during the last termination
}

\author{
N. Bouttes ${ }^{1,2}$, D. Paillard ${ }^{1}$, D. M. Roche ${ }^{1,3}$, C. Waelbroeck ${ }^{1}$, M. Kageyama ${ }^{1}$, A. Lourantou ${ }^{4}$, E. Michel ${ }^{1}$, and L. Bopp ${ }^{1}$ \\ ${ }^{1}$ Laboratoire des Sciences du Climat et de l'Environnement, UMR8212, IPSL-CEA-CNRS-UVSQ, Centre d'Etudes de \\ Saclay, Orme des Merisiers bat. 701, 91191 Gif Sur Yvette, France \\ ${ }^{2}$ NCAS-Climate, Meteorology Department, University of Reading, Reading, RG66BB, UK \\ ${ }^{3}$ Faculty of Earth and Life Sciences, Section Climate Change and Landscape dynamics, Vrije Universiteit Amsterdam, \\ De Boelelaan, 1085, 1081 HV Amsterdam, The Netherlands \\ ${ }^{4}$ LOCEAN, University Paris VI, Paris, France \\ Correspondence to: N. Bouttes (n.bouttes@ reading.ac.uk)
}

Received: 31 May 2011 - Published in Clim. Past Discuss.: 14 June 2011

Revised: 10 December 2011 - Accepted: 12 December 2011 - Published: 20 January 2012

\begin{abstract}
During the last termination (from $\sim 18000$ years ago to $\sim 9000$ years ago), the climate significantly warmed and the ice sheets melted. Simultaneously, atmospheric $\mathrm{CO}_{2}$ increased from $\sim 190 \mathrm{ppm}$ to $\sim 260 \mathrm{ppm}$. Although this $\mathrm{CO}_{2}$ rise plays an important role in the deglacial warming, the reasons for its evolution are difficult to explain. Only box models have been used to run transient simulations of this carbon cycle transition, but by forcing the model with data constrained scenarios of the evolution of temperature, sea level, sea ice, NADW formation, Southern Ocean vertical mixing and biological carbon pump. More complex models (including GCMs) have investigated some of these mechanisms but they have only been used to try and explain LGM versus present day steady-state climates.

In this study we use a coupled climate-carbon model of intermediate complexity to explore the role of three oceanic processes in transient simulations: the sinking of brines, stratification-dependent diffusion and iron fertilization. Carbonate compensation is accounted for in these simulations. We show that neither iron fertilization nor the sinking of brines alone can account for the evolution of $\mathrm{CO}_{2}$, and that only the combination of the sinking of brines and interactive diffusion can simultaneously simulate the increase in deep Southern Ocean $\delta^{13} \mathrm{C}$. The scenario that agrees best with the data takes into account all mechanisms and favours a rapid cessation of the sinking of brines around 18000 years ago, when the Antarctic ice sheet extent was at its maximum. In this scenario, we make the hypothesis that sea ice formation was then shifted to the open ocean where the salty water is quickly mixed with fresher water, which prevents deep
\end{abstract}

sinking of salty water and therefore breaks down the deep stratification and releases carbon from the abyss. Based on this scenario, it is possible to simulate both the amplitude and timing of the long-term $\mathrm{CO}_{2}$ increase during the last termination in agreement with ice core data. The atmospheric $\delta^{13} \mathrm{C}$ appears to be highly sensitive to changes in the terrestrial biosphere, underlining the need to better constrain the vegetation evolution during the termination.

\section{Introduction}

The last termination, which took place between $\sim 18000$ and $\sim 9000$ years ago, is characterized by a global warming (Visser et al., 2003; North Greenland Ice Core Project members, 2004; EPICA community members, 2004; Barker et al., 2009) associated to a shrinking of the ice sheets (Peltier, 1994, 2004; Svendsen et al., 2004). The climate evolved from a cold glacial state (sea surface temperature of -2 to $-6^{\circ} \mathrm{C}$ cooler relative to today in the Southern Ocean; MARGO Project Members, 2009) associated with large Northern Hemisphere ice sheets covering large parts of Europe and North America (Peltier, 2004) to a warmer interglacial state with reduced ice sheets, similar to the modern ones.

The warming in Antarctica is tightly linked to an atmospheric $\mathrm{CO}_{2}$ increase from $\sim 190 \mathrm{ppm}$ at the Last Glacial Maximum (LGM, $\sim 21000$ years ago) to $\sim 260 \mathrm{ppm}$ at the beginning of the Holocene ( $\sim 9000$ years ago) (Monnin et al., 2001; Lourantou et al., 2010). The $\mathrm{CO}_{2}$ rise is crucial to 
explain the warming and shrinking of ice sheets (Berger et al., 1998; Charbit et al., 2005; Ganopolski et al., 2010), in association with the change of insolation. Yet explaining such an increase remains a challenge.

Moreover, the isotopic composition of carbon $\left(\delta^{13} \mathrm{C}\right)$ both in the atmosphere and ocean also evolves during the transition, providing clues and constraints on the evolution of the carbon cycle. The atmospheric $\delta^{13} \mathrm{C}\left(\delta^{13} \mathrm{C}_{\mathrm{atm}}\right)$ presents a $\mathrm{W}$-shape with two negative excursions of $0.5 \%$ during Heinrich event $1(\mathrm{H} 1)$ and the Younger Dryas (YD) (Lourantou et al., 2010). In the ocean the vertical gradient of $\delta^{13} C_{\text {ocean }}$ (the gradient between the upper, $-2000 \mathrm{~m}$ to $0 \mathrm{~m}$, and the deep, $-5000 \mathrm{~m}$ to $-3000 \mathrm{~m}$, ocean $\Delta \delta^{13} \mathrm{C}_{\text {ocean }}=\delta^{13} \mathrm{C}_{\text {upper }}-$ $\delta^{13} \mathrm{C}_{\text {bottom }}$ ) decreases both in the South and North Atlantic. In particular, the deep South Atlantic values increase from around $-0.8 \%$ at the LGM to around $0.4 \%$ in the modern ocean (Hodell et al., 2003; Curry and Oppo, 2005), and more locally from around $-1 \%$ to around $0 \%$ at the location of core MD07-3076Q ( $44^{\circ} \mathrm{S}, 14^{\circ} \mathrm{W},-3770 \mathrm{~m}$ ) (Skinner et al., 2010; Waelbroeck et al., 2011).

Furthermore, during the deglaciation the carbon content of the terrestrial biosphere globally increases as the vegetation expands on previously glaciated areas, although it decreases on areas of the continental shelf that become flooded (Montenegro et al., 2006). The general warming generates a migration of ecosystems towards the poles while the rise of $\mathrm{CO}_{2}$ favours the uptake of carbon by plants (Kaplan et al., 2002; Köhler and Fischer, 2004). Carbon storage by the terrestrial biosphere from the LGM to the preindustrial is estimated by vegetation models to be between $600 \mathrm{GtC}$ and $821 \mathrm{GtC}$ (Kaplan et al., 2002; Brovkin et al., 2002b; Köhler and Fischer, 2004). Reconstructions based on proxy data estimate the range of possible terrestrial carbon change to be 270 $720 \mathrm{GtC}$ from marine records (Bird et al., 1994), and 750$1050 \mathrm{GtC}$ from pollen based estimations (Crowley, 1995).

Since both the atmosphere and the terrestrial biosphere carbon contents increase during the termination, it is generally concluded that the ocean, the largest of the three reservoirs, must be the one that looses carbon. Various hypotheses have been proposed to explain the atmospheric $\mathrm{CO}_{2}$ increase based on modifications of the oceanic carbon content. Most of them focus either on changes in the dynamics of the ocean or on modifications of the marine biology (Archer et al., 2000; Sigman and Boyle, 2000; Fischer et al., 2010; Sigman et al., 2010). Yet the tight link between Antarctic temperature and $\mathrm{CO}_{2}$ (Cuffey and Vimeux, 2001) suggests a simple mechanism instead of a complex association of numerous independent processes. Besides, many of them have been discarded or only account for a small $\mathrm{CO}_{2}$ change such as the coral reef hypothesis (Berger, 1982; Broecker and Peng, 1982; Opdyke and Walker, 1992; Köhler et al., 2005a), modification of winds (Toggweiler et al., 2006; Menviel et al., 2008a), or sea ice extension (Stephens and Keeling, 2000; Archer et al., 2003), as they required unrealistic changes to account for most of the glacial-interglacial $\mathrm{CO}_{2}$ change. Other mechanisms have been confirmed. Enhanced marine biology by iron fertilization during the glacial period, which would then decrease during the deglaciation, is assumed to play a role (Martin, 1990), although of relatively small importance as it could account for a 15-20 ppm change (i.e. approximately $20 \%$ of the $\sim 90 \mathrm{ppm}$ total $\mathrm{CO}_{2}$ change) (Bopp et al., 2003; Tagliabue et al., 2009). Carbonate compensation is a recognized process that amplifies the uptake or loss of carbon by the ocean (Broecker and Peng, 1987; Archer et al., 2000; Brovkin et al., 2007). Finally, changes in the oceanic circulation and mixing can have a significant impact on glacial $\mathrm{CO}_{2}$ (Toggweiler, 1999; Paillard and Parrenin, 2004; Köhler et al., 2005a; Watson and Garabato, 2005; Bouttes et al., 2009; Skinner et al., 2010). In particular, it has been recently shown that the deep stratification induced by enhanced brine sinking can strongly decrease $\mathrm{CO}_{2}$ during the LGM relative to the preindustrial and simultaneously increase the upper to deep ocean $\delta^{13} \mathrm{C}$ gradient, in line with data (Bouttes et al., 2010, 2011).

Moreover, if the sinking of brines is not taken into account, the mechanisms already tested are not sufficient to explain the entire glacial-interglacial $\mathrm{CO}_{2}$ change in models of intermediate complexity (EMICs) or General Circulation Models (GCMs), as there is no physical mechanism to account for a sufficient glacial deep stratification and reduced circulation. Only box models have been able to perform a simulation of the last termination carbon cycle evolution by imposing the evolution of the oceanic circulation and mixing inferred from proxy data (Köhler et al., 2005a). Yet box models can be over-sensitive to changes in high latitudes (Archer et al., 2003). Additionally, because of their simplicity, the reasons for such changes in mixing and circulation that are crucial for the amplitude of the $\mathrm{CO}_{2}$ change (more than $45 \mathrm{ppm}$ of the $\sim 90$ ppm change; Köhler et al., 2005a) could not be tested.

In this study we use a climate model of intermediate complexity to explore the impact of two main oceanic mechanisms during the termination: the sinking of brines, which alters the circulation and mixing of water masses and has not yet been tested in transient simulations, and iron fertilization. Two other processes that are not independent are also considered: the amplification of the effects of the sinking of brines by its feedback on diffusion and the amplification of the oceanic uptake of carbon by the carbonate compensation mechanism.

\section{Methods}

\subsection{The Earth system model of intermediate complexity CLIMBER-2}

We use the CLIMBER-2 coupled intermediate complexity model (Petoukhov et al., 2000; Ganopolski et al., 2001), which is well suited to perform the long runs of several thousands of years requested to study the deglaciation. 
CLIMBER-2's atmosphere has a coarse resolution of $10^{\circ}$ in latitude by $51^{\circ}$ in longitude, which is precise enough to take into account geographical changes, while allowing the model to be fast enough to run long simulations. The ocean is subdivided into three zonally averaged basins with a resolution of 21 depth levels by $2.5^{\circ}$ latitude. It includes a carbon cycle model with the fractionation of ${ }^{13} \mathrm{C}$ (Brovkin et al., 2002a). In addition to modules simulating the ocean, atmosphere, and continental biosphere dynamics, the model also includes a model of carbonate compensation (Brovkin et al., 2007; Archer, 1991). The coupling between CLIMBER-2 and the carbonate compensation model has been discussed in detail in Brovkin et al. (2007). Moreover, three mechanisms have been added in the present study: the sinking of brines, iron fertilization, and stratification-dependent diffusion.

\subsection{Additional mechanisms}

\subsubsection{Iron fertilization}

Iron fertilization relies on the removal of the iron limitation in the "High Nutrient Low Chlorophyll" (HNLC) areas thanks to the supply of glacial atmospheric dust which contains iron (Martin, 1990; Bopp et al., 2003; Brovkin et al., 2007; Tagliabue et al., 2009). According to a proxy-based study of the change of productivity, this effect would have been restrained to the areas north of the modern-day Antarctic polar front (Kohfeld et al., 2005). In the model, it is simply taken into account by forcing the marine biology to use all the nutrients that would otherwise be left in the Atlantic and Indian sectors of the Sub-Antarctic surface ocean $\left(30^{\circ} \mathrm{S}\right.$ to $\left.50^{\circ} \mathrm{S}\right)$ during the glacial period as previously done (Brovkin et al., 2007). This is a simple parameterization of the effect of iron fertilization as the iron cycle is not simulated in the model. As done in Bouttes et al. (2011), we use a parameter to vary this effect between 0 and 1 . This parameter is first set to 1 to explore the maximum potential effect of this mechanism. In the last section, we use a combination of the three mechanisms from Bouttes et al. (2011) in which this parameter is set to 0.3 .

\subsubsection{Sinking of brines}

The version of CLIMBER-2 used here contains a parameterization of the sinking of brines that has been studied in LGM conditions (Bouttes et al., 2010). Brines are small pockets of very salty water rejected by sea ice formation as sea ice is mainly formed of fresh water. In the standard version of CLIMBER-2, the flux of salt rejected to the ocean is mixed in the surface oceanic cell whose volume is quite large due to the coarse resolution. Yet, as brines are very dense because of their high salt content, instead of this dilution they should rapidly sink to the deep ocean where the local topography permits it. During glacial periods, the Antarctic ice sheet progressively extends and covers the continental shelves. In combination with the concomitant sea level fall due to increasing ice sheets volume, it leads to a reduction of the volume of water above the continental shelf. The brines rejected from the intense sea ice formation are less diluted and are released closer to the shelf break. The dense water from brines can then more easily sink along the continental slope to the deep ocean. To avoid the dilution of such an effect, the sinking of brines to the deep ocean has been parameterized in CLIMBER-2 (Bouttes et al., 2010). The relative importance of this brine mechanism is set by the parameter frac, which is the fraction of salt rejected by sea ice formation that sinks to the bottom of the ocean. The rest of the salt $(1-$ frac $)$ is diluted in the corresponding surface oceanic cell as done in the standard version. When frac $=0$ no salt sinks to the abyss as it is entirely mixed in the surface oceanic cell (control simulation), whereas frac $=1$ is the maximum effect of the brine mechanism when all the rejected salt sinks to the bottom of the ocean. This mechanism was shown to result in a net glacial atmospheric $\mathrm{CO}_{2}$ decrease relative to the preindustrial as well as increased $\Delta \delta^{13} \mathrm{C}_{\text {ocean }}$ and increased atmospheric $\delta^{13} \mathrm{C}_{\text {atm }}$ (Bouttes et al., 2010, 2011).

\subsubsection{Stratification-dependent diffusion}

As the sinking of brines tends to modify the stratification state of the ocean (the deep water becomes denser), it should modify the vertical diffusion. The more stratified the ocean becomes, the more energy it requires to mix water masses, implying a lower diffusion. Yet in the standard version of CLIMBER-2, the vertical diffusion coefficient $K_{z}$ is set by a fixed profile and cannot evolve. A parameterization of the vertical diffusion coefficient was therefore introduced (Bouttes et al., 2010) so that vertical diffusion becomes interactive and dependent of the stratification state of the ocean. This allows a more physical representation of the diffusion, which can play a significant role for the ocean circulation (Marzeion et al., 2007) and potentially influence the carbon cycle (Bouttes et al., 2009). The physical parameterization of the vertical diffusion coefficient $K_{z}$ was introduced depending on the vertical density gradient (Marzeion et al., 2007) in the deep ocean (below $2000 \mathrm{~m}$ ) as follows:

$K_{z} \propto N^{-\alpha}$

where $\alpha$ is a parameter and $N=\left(-\frac{g}{\rho_{0}} \frac{\partial \rho}{\partial z}\right)^{\frac{1}{2}}$ is the local buoyancy frequency, with $g$ the gravity acceleration, $\rho_{0}$ a reference density, and $\frac{\partial \rho}{\partial z}$ the vertical density gradient. The parameter $\alpha$ controls the sensitivity of the vertical diffusivity to changes in stratification. A previous study exploring its role during the LGM has shown that it could vary between 0.7 and 0.9 (Bouttes et al., 2011). We first use the maximum value of 0.9 to test the maximum impact of this mechanism. In the last section we use a combination of the three mechanisms from Bouttes et al. (2011) where $\alpha=0.7$.

The impact of the evolution of these mechanisms is first studied in an idealized case with a fixed climate (set to the 
LGM) to assess the effect of each of the mechanisms without the complication of a changing climate. We then explore the evolution of the carbon cycle when the climate evolves from the LGM to the Holocene. To disentangle the effects of the ocean and vegetation, the simulations are run with either interactive or fixed vegetation ("fixed veg").

\subsection{Initial conditions}

The transient simulations start from initial values taken from equilibrium simulations of the Last Glacial Maximum climate and carbon cycle state (Bouttes et al., 2011). The LGM conditions simultaneously imposed in all equilibrium simulations are the $21 \mathrm{kyr} \mathrm{BP}$ insolation (Berger, 1978), LGM ice sheets (Peltier, 2004), and atmospheric $\mathrm{CO}_{2}$ for the radiative code (190 ppm; Monnin et al., 2001; Lourantou et al., 2010). The atmospheric $\mathrm{CO}_{2}$ concentration is prescribed in the radiative code in order to correctly simulate the climate as previously done (Brovkin et al., 2007). The model is thus semi-coupled with respect to the climate and carbon cycle. $\mathrm{CH}_{4}$ and $\mathrm{N}_{2} \mathrm{O}$ are not explicitly considered in the model, but the $\mathrm{CO}_{2}$ level of $190 \mathrm{ppm}$ can be considered as an "equivalent $\mathrm{CO}_{2}$ " for a $\mathrm{CO}_{2}$ level of $167 \mathrm{ppm}$ which would also consider the change of $\mathrm{CH}_{4}$ and $\mathrm{N}_{2} \mathrm{O}$ (Schneider von Deimling et al., 2006). To account for a glacial sea level fall of $\sim 120 \mathrm{~m}$, salinity and mean nutrient concentrations are increased by $3.3 \%$ (Brovkin et al., 2007). To ensure equilibrium for the carbon cycle, glacial simulations were run for 50000 years. The transient simulations analysed in this study start from the equilibrium state of these 50000 year LGM simulations.

At the end of the 50000 year simulation, the global mean surface air temperature with the preindustrial boundary conditions is $14.1^{\circ} \mathrm{C}$. With the LGM conditions, the climate is $3.7^{\circ} \mathrm{C}$ colder. The effect of the dust is not taken into account in this study. According to Schneider von Deimling et al. (2006), it would cool the global climate by an additional $1.35 \pm 0.35^{\circ} \mathrm{C}$, yielding an approximately $5.05 \pm 0.35^{\circ} \mathrm{C}$ colder climate during the LGM compared to the preindustrial.

With no additional mechanism nor carbonate compensation, the obtained $\mathrm{LGM} \mathrm{CO}_{2}$ is around $300 \mathrm{ppm}$. When carbonate compensation is taken into account, $\mathrm{CO}_{2}$ is approximately $260 \mathrm{ppm}$. In the other simulations carbonate compensation is always included. With iron fertilization the LGM $\mathrm{CO}_{2}$ is around $230 \mathrm{ppm}$, it falls to around $215 \mathrm{ppm}$ with the sinking of brines. For the stratification-dependent diffusion, the $\alpha$ parameter is first set to its maximum value inferred from a previous study, i.e. 0.9 (Bouttes et al., 2011). The $190 \mathrm{ppm}$ level is reached with either the sinking of brines combined with the stratification-dependent diffusion or the sinking of brines with iron fertilization. The effect of the different processes influencing the $\mathrm{CO}_{2}$ level during the LGM, including the solubility effect and the role of the additional mechanisms, has been previously studied in Bouttes et al. (2009, 2010, 2011).

\subsection{Evolution of the forcing}

During deglaciation, the insolation, sea level, ice sheets, and $\mathrm{CO}_{2}$ evolved. The insolation evolution is calculated from Berger (1978). In the first part of this study, the $\mathrm{CO}_{2}$ evolution (Monnin et al., 2001; Lourantou et al., 2010) is imposed for the climate modules of the model as it is used to compute the changing radiative forcing, but it is not used for the carbon cycle part of the model. The $\mathrm{CO}_{2}$ data are on the EDC3 age scale (Parrenin et al., 2007). Prescribing the $\mathrm{CO}_{2}$ level allows us to obtain a coherent climate even when the $\mathrm{CO}_{2}$ calculated by the carbon cycle is different from the one recorded in ice cores. Because we focus on the evolution of $\mathrm{CO}_{2}$ only, the effect of $\mathrm{CH}_{4}$ and $\mathrm{N}_{2} \mathrm{O}$ is not considered. In the second part, the model is used in an interactive mode, i.e. the $\mathrm{CO}_{2}$ calculated by the carbon cycle module is now used to compute the radiative scheme, no $\mathrm{CO}_{2}$ value is prescribed.

The sea level change is taken into account by changing the global mean salinity and nutrient concentrations based on sea level data (Waelbroeck et al., 2002). This is a global effect that does not take into account the addition of fresh water fluxes in restricted areas. Indeed, although abrupt events took place during the last termination (Keigwin et al., 1991), rapid climate changes that can be triggered by the addition of fresh water fluxes (Ganopolski and Rahmstorf, 2001) are beyond the scope of this study, which focuses on the general trends during the transition. The geography is thus not directly changed and the closing-opening of the Bering Strait is not taken into account.

The ice sheet evolution is simply imposed by interpolation between LGM and Late Holocene states based on the sea level data. First, a sea level coefficient is computed:

$s l_{\text {coeff }}=\frac{s l_{1}-s_{\text {ctrl }}}{s l_{\text {lgm }}-s l_{\text {ctrl }}} \quad$ and $\quad 0<s l_{\text {coeff }}<1$

with sl the sea level of the considered time step, $\mathrm{sl}_{\mathrm{ctrl}}$ the modern sea level and sl lgm the LGM sea level. Then, from $s l_{\text {coeff }}$ we compute the area of the Northern Hemisphere ice sheets in a given latitudinal sector as:

arealgm $\times \mathrm{sl}_{\text {coeff }}^{\frac{2}{3}}$

with area $a_{\text {gm }}$ the LGM ice sheets area (Peltier, 2004). The northern limit of the ice sheets is given by the CLIMBER-2 continental limit. The southern limit is computed from this area. The height of the ice sheets is calculated as:

oro $_{\text {ctrl }}+\left(\right.$ orolgm $_{\text {lgm }}-$ oro $\left._{\text {crtl }}\right) \times \mathrm{sl}_{\text {coeff }}^{\frac{1}{3}}$

with oro ${ }_{\text {ctrl }}$ the modern orography and oro Igm $_{\text {gm }}$ th LM orography (Peltier, 2004). This very simple ice sheet evolution formulation was initially developed for longer term simulations for which no information about ice sheet extent and height was precisely known. It provides an ice sheets evolution consistent with the sea level evolution. Such a parameterization should allow the study of a full glacial-interglacial cycle in the future. 
a

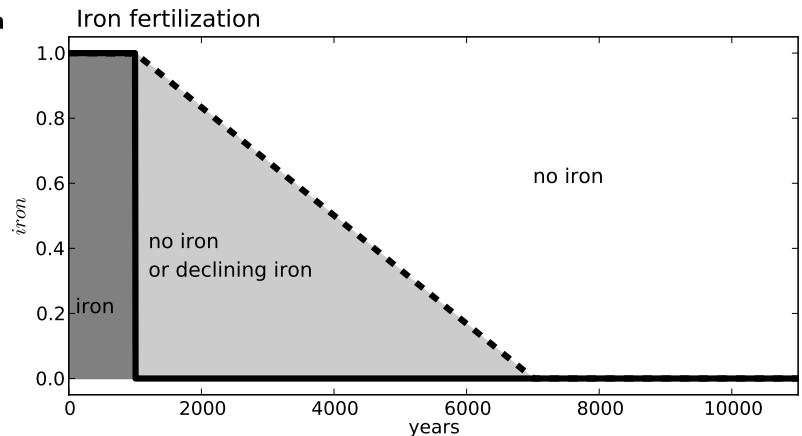

b

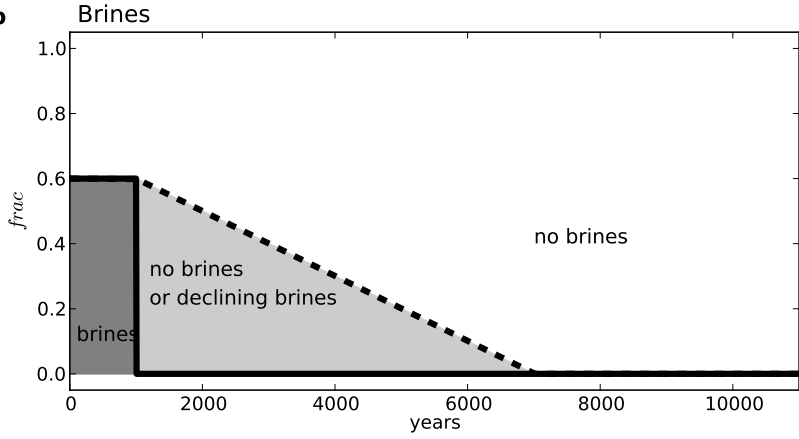

brutal halt of iron / brines ("abrupt")

. - - linear decline of iron / brines ("linear")

Fig. 1. Evolution scenarios for iron fertilization and the sinking of brines with a constant climate. The two processes are active at the beginning of the simulations; then they stop. This stop can be sudden or follow a linear decline.

In the following we test three oceanic mechanisms (iron fertilization, sinking of brines and stratification-dependent diffusion). We explore different scenarios for their evolution in order to simulate the $\mathrm{CO}_{2}$ and atmospheric and oceanic $\delta^{13} \mathrm{C}$ evolution during the last deglaciation, and compare the results with proxy data to constrain the possible scenarios.

\section{Results and discussion}

\subsection{Evolution of the mechanisms under a constant LGM climate: sensitivity studies}

We first analyze sensitivity studies to compare the impact of the mechanisms (with different scenarios) on the evolution of the carbon cycle with a constant climate and assess the role of each mechanism alone. In these idealized simulations the climate is set by glacial boundary conditions. Atmospheric $\mathrm{CO}_{2}$ is prescribed to $190 \mathrm{ppm}$ (Monnin et al., 2001); the northern ice sheets (Peltier, 2004) and the orbital parameter values (Berger, 1978) correspond to the situation at $21 \mathrm{kyr}$ BP. a

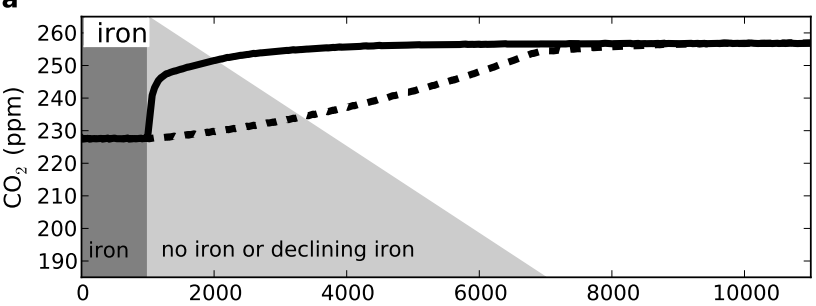

b
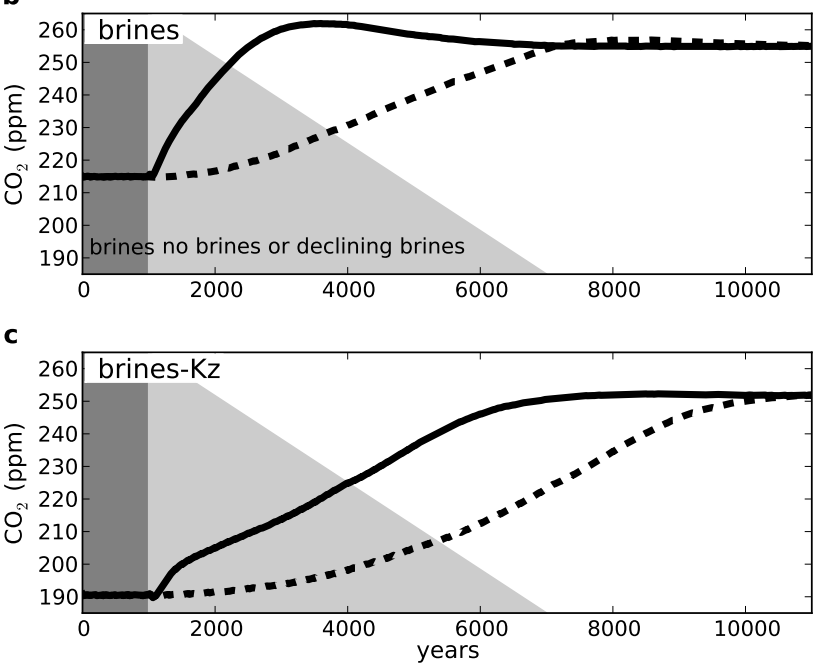

brutal halt of iron / brines ("abrupt")

- - l linear decline of iron / brines ("linear")

Fig. 2. Evolution of atmospheric $\mathrm{CO}_{2}$ with a constant climate for three mechanisms: (a) iron fertilization, (b) sinking of brines and (c) sinking of brines and interactive vertical diffusion.

\subsubsection{Scenarios for the sinking of brines and iron fertilization}

Two idealized scenarios are tested for the evolution of the sinking of brines and iron fertilization (Fig. 1). Both mechanisms are active at the beginning of the simulations, and then stopped. This halt can either be instantaneous (scenario "abrupt") or linear in time (scenario "linear"). The evolution imposed for the brines and iron mechanism is the same so that we can compare their responses in time.

\subsubsection{Impact of stopping iron fertilization}

The halt of iron fertilization leads to an increase of atmospheric $\mathrm{CO}_{2}$ as the biological pump is weakened (Fig. 2a). $\mathrm{CO}_{2}$ increases by $29 \mathrm{ppm}$ (Table 1 ) in both scenarios. The equilibrium is rapidly reached for the abrupt halt of iron fertilization (Scenario "abrupt"). To compare the time needed by the system to reach a near-equilibrium state, we consider the time when the anomaly of a considered variable (defined as the difference between its value and its initial value) has 


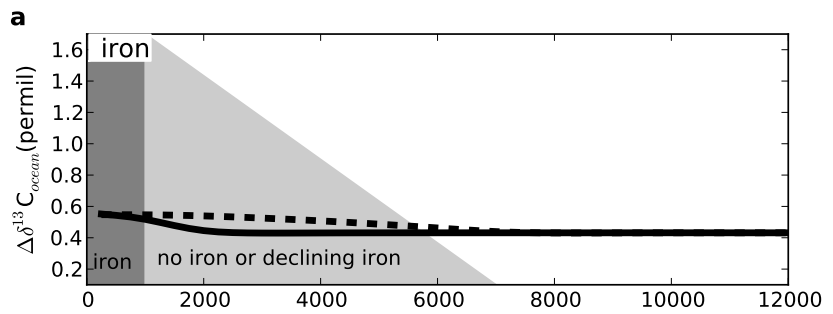

b
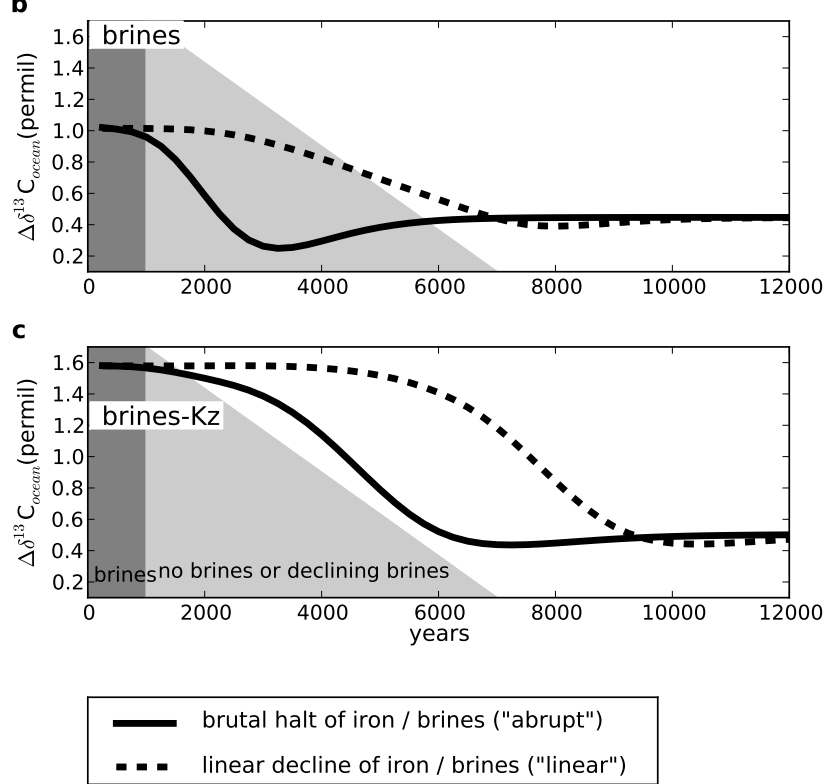

Fig. 3. Evolution of oceanic $\Delta \delta^{13} \mathrm{C}_{\text {ocean }}$ with a constant climate for three mechanisms: (a) iron fertilization, (b) sinking of brines and (c) sinking of brines and interactive vertical diffusion.

Table 1. Amplitude of change between the beginning and the end of the simulations under a constant glacial climate as observed on Figs. 2, 3 and 4. "Iron" corresponds to iron fertilization, "Brines" to the sinking of brines, and Brines- $K_{z}$ to the sinking of brines and interactive diffusion.

\begin{tabular}{lclc}
\hline & $\begin{array}{c}\mathrm{CO}_{2} \\
(\mathrm{ppm})\end{array}$ & $\begin{array}{l}\Delta \delta^{13} \mathrm{C}_{\text {ocean }} \\
(\% \circ)\end{array}$ & $\begin{array}{c}\delta^{13} \mathrm{C}_{\mathrm{atm}} \\
(\% \circ)\end{array}$ \\
\hline Iron & 29 & -0.12 & -0.25 \\
Brines & 40 & -0.57 & -0.25 \\
Brines- $K_{z}$ & 61 & -1.1 & -0.34 \\
\hline
\end{tabular}

reached $95 \%$ of the anomaly of the equilibrium state (Table 2). In the "abrupt" scenario, the system has reached $95 \%$ of the equilibrium value $\sim 100$ years after the stop of fertilization, i.e. very quickly compared to the time scale of the termination (a few thousand years). In the "linear" scenario, the response of the carbon cycle follows the forcing and it takes $\sim 4400$ years for the system to reach $95 \%$ of the equilibrium value.
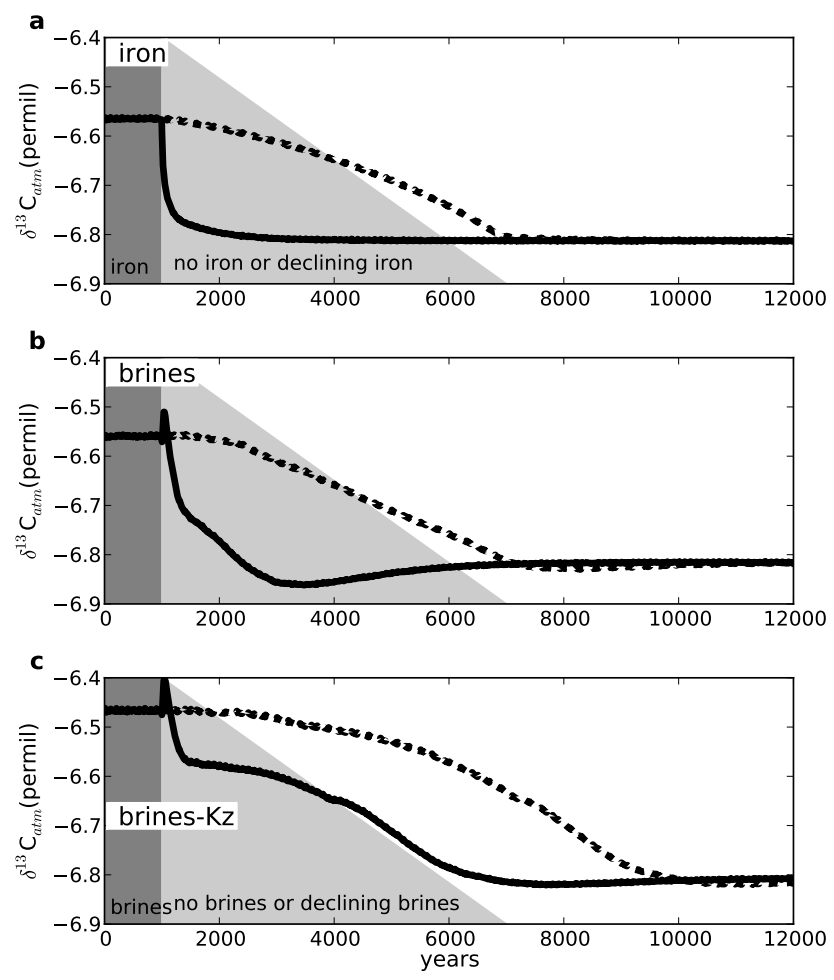

brutal halt of iron / brines ("abrupt")
- - - linear decline of iron / brines ("linear")

Fig. 4. Evolution of atmospheric $\delta^{13} \mathrm{C}_{\text {atm }}$ with a constant climate for three mechanisms: (a) iron fertilization, (b) sinking of brines and (c) sinking of brines and interactive vertical diffusion.

The impact of iron fertilization on $\delta^{13} \mathrm{C}_{\text {ocean }}$ is very small (Fig. 3a). We consider the mean vertical gradient $\left(\Delta \delta^{13} \mathrm{C}_{\text {ocean }}\right)$ of $\delta^{13} \mathrm{C}_{\text {ocean }}$ in the Atlantic between the upper $(-2000 \mathrm{~m}$ to $0 \mathrm{~m})$ and deep $(-5000 \mathrm{~m}$ to $-3000 \mathrm{~m})$ ocean. The modification of the gradient is only $\sim 0.1 \%$ o (Table 1 ). On the other hand, the change of $\delta^{13} \mathrm{C}_{\mathrm{atm}}$ is larger (Fig. 4a) as it is decreased by $0.25 \%$ (Table 1 ).

\subsubsection{Impact of stopping the sinking of brines}

Stopping the brine sinking mechanism leads to a larger atmospheric $\mathrm{CO}_{2}$ increase than stopping the iron fertilization (Fig. 2b) with a change of $40 \mathrm{ppm}$ (Table 1). This effect of the brine sinking is not the maximum possible effect (which would be obtained for frac $=1$ ), but corresponds to a more realistic case (frac $=1$ is very idealistic as it would require no mixing at all) with frac $=0.6$, which is in the middle of the range of probable values according to proxy data (Bouttes et al., 2011). The response of the system to the abrupt halt of brine sinking takes more time than in the case of the iron fertilization. In the abrupt scenario, $95 \%$ of the equilibrium value is reached 900 years after the stop (Table 2). Indeed, 
Table 2. Time for the anomaly of the considered variable (defined as the difference between its value and the initial value) to reach $95 \%$ of the equilibrium anomaly value (equilibrium anomaly value taken as the difference between the value at year 12000 of the simulations and the initial value) under a constant glacial climate for (a) $\mathrm{CO}_{2}$, (b) $\Delta \delta^{13} \mathrm{C}_{\text {ocean }}$, and (c) $\delta^{13} \mathrm{C}_{\mathrm{atm}}$. "Iron" corresponds to iron fertilization, "Brines" to the sinking of brines, and Brines- $K_{z}$ to the sinking of brines and interactive diffusion. The two scenarios for iron fertilization and the sinking of brines ("abrupt" and "linear") are defined in Fig. 1.

\begin{tabular}{llc}
\hline (a) $\mathrm{CO}_{2}$ & & \\
\hline & "abrupt" scenario & "linear" scenario \\
\hline Iron & 120 years & 4360 years \\
Brines & 900 years & 4370 years \\
Brines- $\mathrm{K}_{z}$ & 4270 years & 7440 years \\
\hline (b) $\Delta \delta{ }^{13} \mathrm{C}_{\text {ocean }}$ & \\
\hline Iron & 1250 years & 6250 years \\
Brines & 1250 years & 5750 years \\
Brines- $K_{z}$ & 5000 years & 8250 years \\
\hline (c) $\delta{ }^{13} \mathrm{C}_{\text {atm }}$ & & \\
\hline Iron & 1270 years & 5890 years \\
Brines & 1270 years & 5850 years \\
Brines- $K_{z}$ & 5140 years & 8570 years \\
\hline
\end{tabular}

the brine sinking mechanism involves changes in the thermohaline circulation through enhanced vertical stratification (Bouttes et al., 2010). The thermohaline circulation takes more time to equilibrate than the biological activity. Halting the sinking of brines stops the transport of salt to the deep ocean. This transport of salt during the glacial period is responsible for a density increase of the deep waters compared to upper waters and therefore a greater vertical stratification relative to the preindustrial. This leads to a more isolated glacial deep water mass that can store a larger amount carbon. When the vertical salt transport is stopped, the stratification breaks down and the thermohaline circulation changes: both the North Atlantic and Southern ocean overturning cells become more vigorous (Fig. 5). Indeed, with the stratification induced by the sinking of brines the maximum of the NADW export is around $15 \mathrm{~Sv}$ compared to around $20 \mathrm{~Sv}$ without it. When the stratification breaks down, the formation of deep water intensifies rapidly to $22 \mathrm{~Sv}$ in around 1500 years. It then decreases more slowly back to $20 \mathrm{~Sv}$. The atmospheric $\mathrm{CO}_{2}$ follows the evolution of the oceanic circulation as the carbon stored in the abyss is progressively released when the overturning circulation increases.

In the "linear" scenario the thermohaline circulation has more time to adapt and the evolution is smoother. The maximum export of NADW increases gradually from $15 \mathrm{~Sv}$ to around $20 \mathrm{~Sv}$, the latter being reached after around
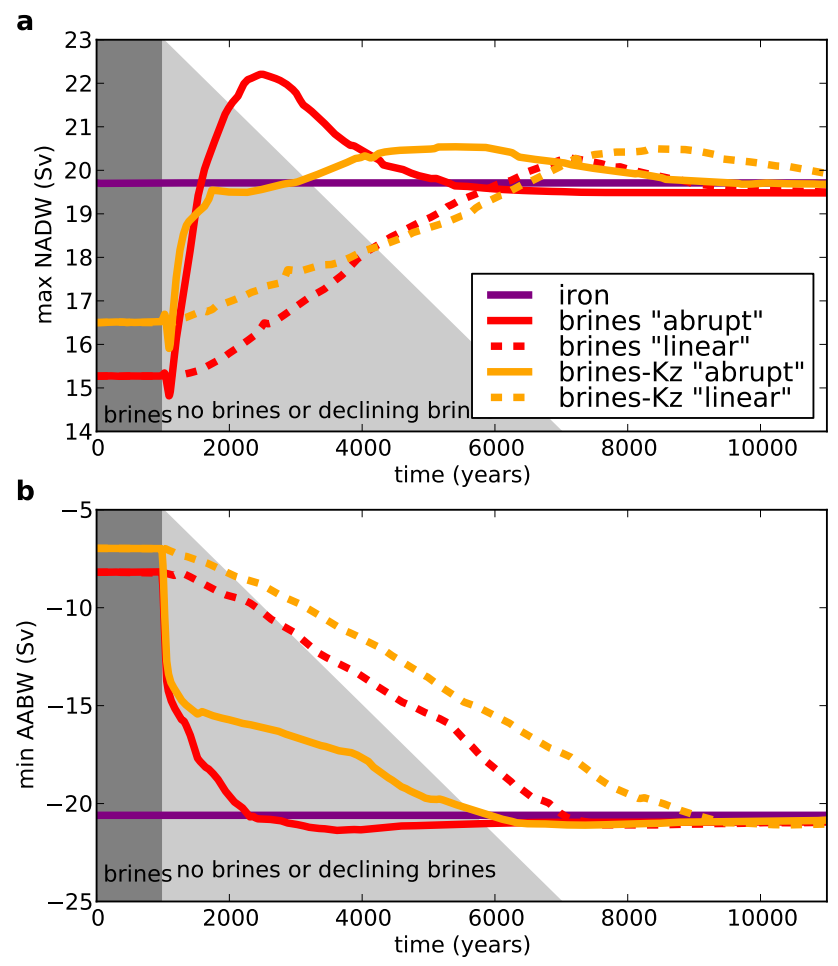

Fig. 5. Evolution of the thermohaline circulation with a constant climate. (a) Evolution of the maximum value of the North Atlantic stream function $(\mathrm{Sv})$ and (b) evolution of the minimum value of the Southern Ocean stream function (Sv).

4500 years (Fig. 5). Hence, the time to reach $95 \%$ of the equilibrium value is very similar to the time in the experiment with iron fertilization $(\sim 4400$ years, Table 2$)$.

The amplitude of the $\Delta \delta^{13} \mathrm{C}_{\text {ocean }}$ decrease is more significant with the brine sinking mechanism than with the iron fertilization mechanism (Fig. 3), with a decrease of the vertical gradient of $\sim 0.57 \%$. The induced stratification has a large impact on the vertical $\delta^{13} \mathrm{C}_{\text {ocean }}$ gradient as it reduces the mixing between the ${ }^{13} \mathrm{C}$ enriched upper water and ${ }^{13} \mathrm{C}$ depleted deep waters. As a result, it better preserves the vertical gradient due to biological activity (Bouttes et al., 2010). In contrast, the change in $\delta^{13} \mathrm{C}_{\text {atm }}$ is similar to the one induced by suppression of the iron fertilization. The sinking of brines has an important impact on both $\Delta \delta^{13} \mathrm{C}_{\text {ocean }}$ and $\delta^{13} \mathrm{C}_{\text {atm }}$ because it efficiently increases upper ocean $\delta^{13} \mathrm{C}$ and decreases deep ocean $\delta^{13} \mathrm{C}$. When the stratification breaks down, it leads to a decrease of upper ocean $\delta^{13} \mathrm{C}$ and $\delta^{13} \mathrm{C}_{\mathrm{atm}}$. The iron fertilization mechanism has a smaller effect on $\Delta \delta^{13} \mathrm{C}_{\text {ocean }}$ partly because remineralization not only takes place in the deep ocean, but also above. Even if the surface $\delta^{13} \mathrm{C}_{\text {ocean }}$ is significantly increased with iron fertilization (as well as $\delta^{13} \mathrm{C}_{\mathrm{atm}}$ ), the deep $(-5000 \mathrm{~m}$ to $-3000 \mathrm{~m}) \delta^{13} \mathrm{C}_{\text {ocean }}$ is relatively less modifed (the remineralization also releases ${ }^{12} \mathrm{C}$ in intermediate waters) and therefore $\Delta \delta^{13} \mathrm{C}_{\text {ocean }}$ changes less than with the sinking of brines. 


\subsubsection{Impact of stopping the sinking of brines with the stratification-dependent diffusion included}

The addition of the stratification-dependent diffusion mainly amplifies the impact of the brine sinking mechanism. Because of the lower vertical diffusion induced by the enhanced vertical density gradient, the deep water mass is even more isolated at the beginning of the simulation. It yields a lower initial $\mathrm{CO}_{2}$ level (Fig. 2c), higher initial $\Delta \delta^{13} \mathrm{C}_{\text {ocean }}$ (Fig. 3c) (Bouttes et al., 2011), and higher initial $\delta^{13} \mathrm{C}_{\text {atm }}$ (Fig. 4c). When the brine sinking stops, it thus leads to a larger $\mathrm{CO}_{2}$ increase reaching $61 \mathrm{ppm}$ (Table 1).

Moreover, the interactive diffusion induces a delay in the oceanic circulation response. After a first rapid increase of the export of North Atlantic Deep Water similar to the one in the simulation without the interactive diffusion (it reaches $20 \mathrm{~Sv}$ after around 500 years), the maximum export of NADW very slowly increases of around $1 \mathrm{~Sv}$ in around 3500 years (Fig. 5). As the stratification breaks down, the diffusion coefficent which is interactively computed increases as well. Because the mixing increases, it tends to diminish the density gradient and the export of water. As a consequence, it leads to the same delay in the carbon evolution. Indeed, with the interactive diffusion, the diffusion coefficient is lower at the beginning of the simulation because of the enhanced stratification. When the stratification collapses, the diffusion coefficient progressively increases because the vertical density gradient decreases. Yet it remains smaller than in the simulation without interactive diffusion (until the vertical density gradient is the same), so that the mixing is less important and the change of circulation smaller than in the fixed diffusion simulation. Because of this delay, the $\mathrm{CO}_{2}$ reaches $95 \%$ of the equilibrium value $\sim 4300$ years after the sudden halt of brine sinking, i.e. $\sim 3400$ years later than with the brines mechanism alone. Similarly, in the "linear" scenario it takes $\sim 7400$ years for the system to reach $95 \%$ of the equilibrium value, i.e. $\sim 3100$ years later compared to the brines alone.

The halt of the sinking of brines with the stratificationdependent diffusion also leads to a decrease of both $\delta^{13} \mathrm{C}_{\mathrm{atm}}$ and $\Delta \delta^{13} \mathrm{C}_{\text {ocean }}$. The amplitude is slightly greater than with brines alone for $\delta^{13} \mathrm{C}_{\mathrm{atm}}$ (change of $0.34 \%$, Table 1) because of the amplification due to the interactive diffusion. The amplitude is, however, much higher for $\Delta \delta^{13} \mathrm{C}_{\text {ocean }}$ with the interactive diffusion, which plays an important role in the ocean. It isolates even more the deep ocean which strongly decreases the deep ocean $\delta^{13} \mathrm{C}$. The additional delay because of the progressive return to modern diffusion values is apparent in both cases with $\delta^{13} \mathrm{C}$ reaching $95 \%$ of the equilibrium value approximately 3800-3900 years later than with brines alone. In the "linear" scenario, the ocean has more time to adapt and this delay is reduced to $2500-2700$ years.
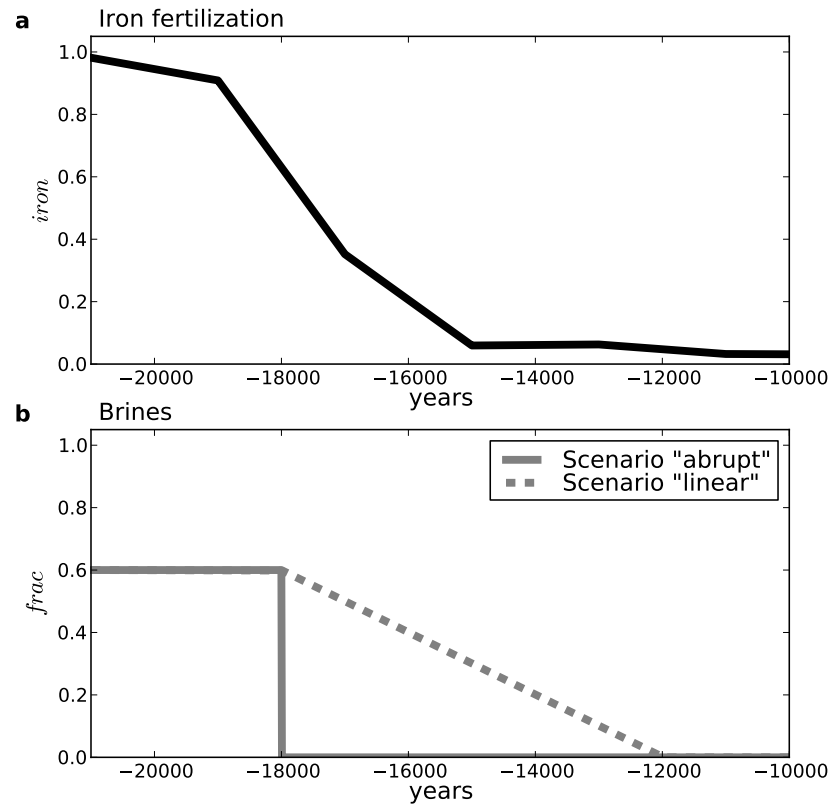

Fig. 6. Evolution scenarios for (a) iron fertilization and (b) the sinking of brines during the last deglaciation. The two processes are active at the beginning of the simulations then stop. The iron fertilization decline follows the dust transport as recorded in ice cores (Wolff et al., 2006) on the EDC3 age model (Parrenin et al., 2007). The halt of the sinking of brines follows two scenarios: a sudden halt ("abrupt") or a linear decline ("linear").

\subsection{Evolution of the mechanisms during the last deglaciation with prescribed $\mathrm{CO}_{2}$}

We now consider iron fertilization and the sinking of brines in the context of the global warming and ice sheet retreat of the last deglaciation. As described in the method section, in these simulations the three boundary conditions that are the atmospheric $\mathrm{CO}_{2}$, ice sheets, and orbital parameters vary through time. Atmospheric $\mathrm{CO}_{2}$ and ice sheets vary according to proxy data. The vegetation is either interactively calculated by the terrestrial biosphere model (VECODE) and therefore evolving with time according to the climate and $\mathrm{CO}_{2}$ concentration imposed or fixed to the glacial distribution as calculated in the glacial simulations ("fixed veg") in order to separate the impact of the ocean from the one of the vegetation. Iron fertilization and the sinking of brines follow different scenarios (Fig. 6). The evolution of iron fertilization is based on iron flux records (Wolff et al., 2006) on the EDC3 age model (Parrenin et al., 2007). It is indeed modulated by a parameter iron that can evolve between 0 and 1 following the iron flux record. The parameter is at its maximum (iron =1) at the Last Glacial Maximum and close to 0 at the beginning of the Holocene (Fig. 6a). The evolution of the sinking of brines (which can not be directly constrained) is set by the same two idealised scenarios as in the previous part. 
The halt of the sinking of brines imposed in the model would, in reality, be due to the change of topography around Antarctica (Fig. 7). Indeed, the sinking of brines would depend on the volume of water above the shelves. It would thus depend on two variables: the evolution of sea level and the advance/retreat of the Antarctic ice sheet on the shelves. During interglacials, the volume of water above the continental shelves is important and some mixing of the salt rejected by sea ice formation happens. The salty dense water can thus not easily sink to the bottom of the ocean (Fig. 7a). During the glaciation, the Antarctic ice sheet progressively increases both in volume and extension (Fig. 7b). Because of the extension of the ice sheet and the sea level fall, the volume of water above the continental shelves is reduced and the salt less diluted. Moreover, the release of salt increases as more sea ice is formed (in particular as the seasonality seems to increase; Gersonde et al., 2005). The salt rejected by sea ice formation can accumulate more and create very dense water susceptible to flow more easily down to the abyss. This is modelled by an increase of the fraction of salt that sinks to the deep ocean, the frac parameter. When the ice sheet reaches its maximum extent, i.e. when the continental shelves are covered, a few thousand years after the Last Glacial Maximum (Ritz et al., 2001; Huybrechts, 2002), the sea ice formation is shifted to the open ocean. The absence of shelf where the brines sink, accumulate, and create very dense water susceptible to flow down to the abyss, prevents the deep sinking of brines (Fig. 7c). In the open ocean, the dilution of the brines released by sea ice is more important and the effect of the brine-generated dense water disappears. If the continental shelves are all covered simultaneously, it results in an abrupt halt of the sinking of brines. Alternatively, the halt of the sinking of brines can be linked to the sea level rise, which increases the volume of water above the continental shelf leading to more mixing and less sinking of dense water. It corresponds to a more progressive reduction of the sinking of brines, which can be first approximated by a linear decrease. These two extreme scenarios ("linear" and "abrupt") of the halt of the sinking of brines are both tested. The two scenarios explore the two extreme cases, a more probable one would lie between the two. According to proxy data, the West Antarctic ice sheet advanced to the outer shelf in most regions (Anderson et al., 2002). Because the glaciation and deglaciation are not symetrical with respect to the sea level change and advance and retreat of the Antarctic ice sheet on the continental shelves, the evolution of the sinking of brines would also not be symetrical. In particular, according to data, the Antarctic ice sheet melting starts later than the northern ones, around 14 kyr BP (Clark et al., 2009; Mackintosh et al., 2011). At that time, the sea level is already higher than at the LGM because the Northern ice sheet started to melt earlier. In association with the input of fresh water from the melting of the Antarctic ice sheet, it would prevent the important sinking of the brines to happen again. It is thus not possible to exclude that some sinking of the brines occurred again
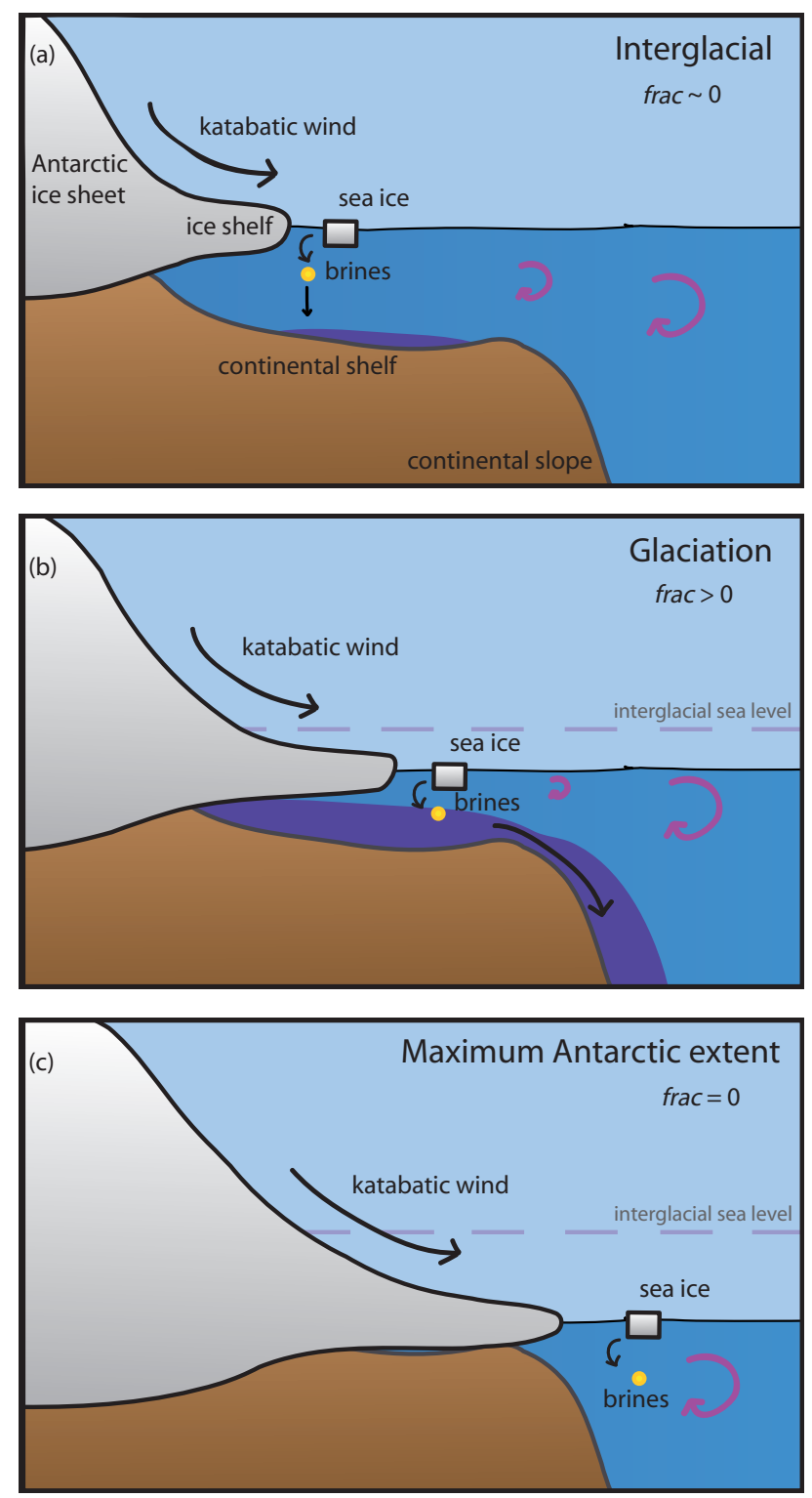

Fig. 7. Schematic representation of the sinking of brines during (a) interglacial, (b) glacial and (c) deglacial periods. The main drivers of the fraction of salt sinking to the deep ocean (frac) are the Antarctic ice sheet extent on the continental shelf and sea level which govern the volume of water above the continental shelf. The less water there is, the less brines are mixed and the more they can sink into the deep ocean. When sea ice formation is shifted to the open ocean, brines are mixed and the sinking stops.

(although not at the very beginning of the deglaciation since it was inhibited by the presence of the Antarcic ice sheet on the shelves), yet it would be relatively less important. However, this possibility is beyond the scope of this study, which explores the mean trend during the deglaciation, and would require further work to focus on the effect of a brief activation of the sinking of brines during the deglaciation, probably in link with more rapid events. 

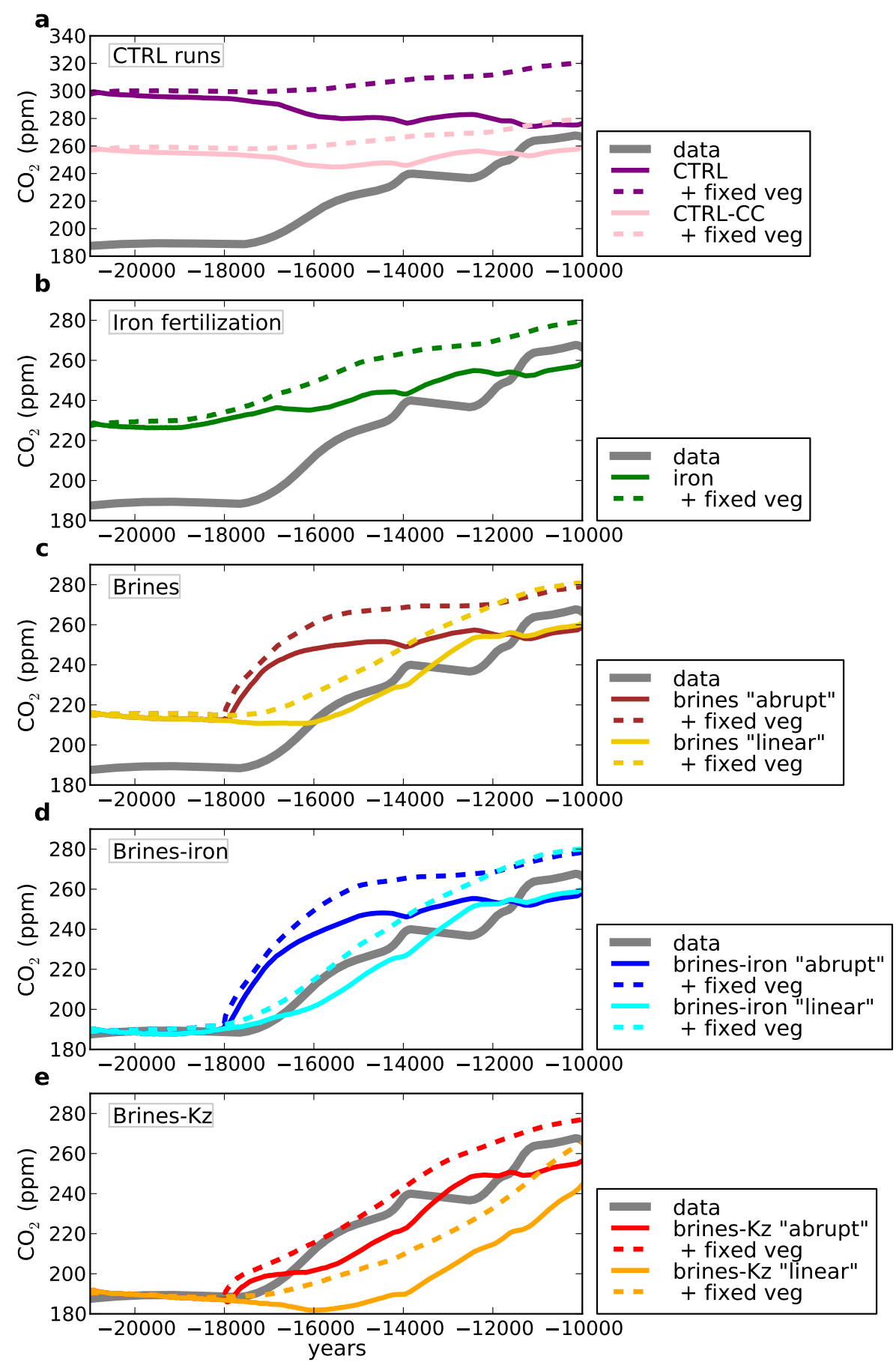

Fig. 8. Evolution of atmospheric $\mathrm{CO}_{2}$ during the last deglaciation with different oceanic mechanisms and comparison with data: (a) control (CTRL) runs without and with carbonate compensation (CC), all other simulations are with carbonate compensation, (b) simulations with iron fertilization, (c) simulations with the sinking of brines (two scenarios as defined in Fig. 6), (d) simulations with the sinking of brines (two scenarios as defined in Fig. 6) and iron fertilization, (e) simulations with the sinking of brines (two scenarios as defined in Fig. 6) and interactive vertical diffusion coefficient $\left(K_{z}\right)$. Each simulation has either an interactive vegetation or a fixed glacial vegetation ("fixed veg"). The data are from Monnin et al. (2001); Lourantou et al. (2010). 


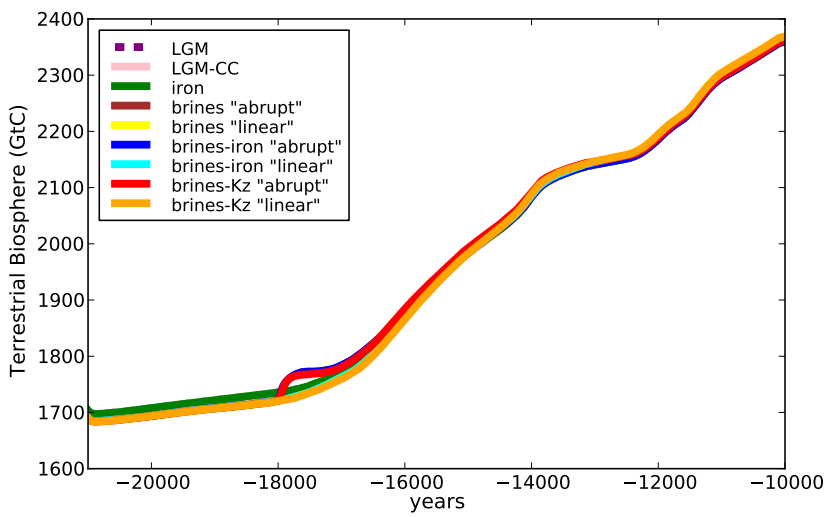

Fig. 9. Evolution of the carbon stock from the terrestrial biosphere $(\mathrm{GtC})$ during the deglaciation for the simulations as defined in Fig. 6, when the terrestrial biosphere is interactive.

\subsubsection{Control simulations of the evolution of the carbon cycle during the deglaciation}

Without carbonate compensation, the initial value of atmospheric $\mathrm{CO}_{2}$ at -21000 years is $298 \mathrm{ppm}$ (Fig. 8a) due to the opposite effects of oceanic and vegetation changes (Brovkin et al., 2007; Bouttes et al., 2010). The effect of changing the boundary conditions to the LGM ones (orbital parameters, ice sheets and atmospheric $\mathrm{CO}_{2}$ ) is to decrease $\mathrm{CO}_{2}$ by $24 \mathrm{ppm}$, mainly because of the colder climate which results in greater solubility of $\mathrm{CO}_{2}$ in the glacial ocean compared to the preindustrial. The increase of nutrient concentrations due to the sea level fall of approximately $120 \mathrm{~m}$ also reduces $\mathrm{CO}_{2}$ relative to the preindustrial since the biological production is enhanced. This effect is relatively small as $\mathrm{CO}_{2}$ is reduced by $3 \mathrm{ppm}$. Yet, the sea level fall also increases the global oceanic salinity, which decreases $\mathrm{CO}_{2}$ solubility in the ocean, thus increasing $\mathrm{CO}_{2}$. The simulated $\mathrm{CO}_{2}$ increase due to the global salinity increase is of $7 \mathrm{ppm}$. Finally, the terrestrial biosphere carbon content is reduced by $\sim 650 \mathrm{GtC}$ compared to the Holocene (Fig. 9), which releases carbon into the atmosphere leading to an increase of $\mathrm{CO}_{2}$ of $38 \mathrm{ppm}$ in the model. This effect does not take into account the increase of terrestrial biosphere carbon content on shelf areas previously flooded, which would be between 182 and $417 \mathrm{GtC}$ (Montenegro et al., 2006; Joos et al., 2004). Although the ocean partially stores some of the released carbon, part of it remains in the atmosphere. This effect prevails and the simulated atmospheric $\mathrm{CO}_{2}$ is $298 \mathrm{ppm}$ at the $\mathrm{LGM}$, a value very different from the data $(\sim 190 \mathrm{ppm})$. For more details on these different effects we refer to Brovkin et al. (2007) and Bouttes et al. (2010).

From this initial state, in the control glacial simulation without carbonate compensation (CTRL), the atmospheric $\mathrm{CO}_{2}$ slightly decreases from $298 \mathrm{ppm} 21000$ years ago to 280 ppm 10000 years ago when the terrestrial biosphere evolution is taken into account (Fig. 8a) whereas $\mathrm{CO}_{2}$ increases to $320 \mathrm{ppm}$ when the vegetation is fixed. $\mathrm{CO}_{2}$ increases because of the warming and diminished global oceanic nutrient concentrations. The decrease of salinity tends to counteract the increase, but the overall evolution is still a $\mathrm{CO}_{2}$ increase when the vegetation is fixed ("fixed veg"). When the evolution of vegetation is accounted for (interactive vegetation), it results in a $\mathrm{CO}_{2}$ decrease as the terrestrial biosphere carbon content progressively increases (Fig. 9). This effect prevails leading to the simulated decrease of atmospheric $\mathrm{CO}_{2}$.

With carbonate compensation (CTRL-CC), the uptake of carbon by the ocean is amplified during the LGM, which results in a lower glacial $\mathrm{CO}_{2}$ in the initial state, around $260 \mathrm{ppm}$ (Fig. 8a). When the vegetation is fixed, the evolution of $\mathrm{CO}_{2}$ in the transient simulation is the same as in the previous simulation with a $20 \mathrm{ppm}$ increase. When the vegetation is interactive, the $\mathrm{CO}_{2}$ remains roughly constant because the terrestrial biosphere carbon content increases, which acts to decrease $\mathrm{CO}_{2}$ and counteracts the $\mathrm{CO}_{2}$ increase from oceanic processes.

The evolution of $\delta^{13} \mathrm{C}_{\text {ocean }}$ in the ocean is a good indicator of the physical processes involved and an important constraint. One of the more striking features of the changes from the glacial to the interglacial state is the increase in the deep Southern Ocean $\delta^{13} C_{\text {ocean }}$ value. Hence, we focus on the evolution of $\delta^{13} \mathrm{C}$ at one site in the deep Southern Ocean. We compare the simulation results to the record from core MD07-3076Q (Skinner et al., 2010; Waelbroeck et al., 2011), which has a good resolution and is well dated. The simulated $\delta^{13} \mathrm{C}_{\text {ocean }}$ at that site shows an increase of $\sim 0.3 \%$ only (Fig. 10a), a small amplitude compared to the measured total variation of $\sim 1.3 \%$.

Atmospheric $\delta^{13} \mathrm{C}_{\mathrm{atm}}$ is sensitive to the evolution of the terrestrial biosphere (Fig. 11a). The difference between the simulated $\delta^{13} \mathrm{C}_{\mathrm{atm}}$ with fixed vegetation ("fixed veg") and interactive vegetation gets greater with time and equals $\sim 0.4 \%$ at -10000 years. With fixed vegetation, the changes in $\delta^{13} \mathrm{C}_{\mathrm{atm}}$ are only due to processes taking place in the ocean. As $\delta^{13} \mathrm{C}_{\text {ocean }}$ does not change much, it induces a constant $\delta^{13} \mathrm{C}_{\mathrm{atm}}$ value. The difference between the simulations with interactive vegetation and "fixed veg" is only due to the terrestrial biosphere whose carbon content progressively increases (Fig. 8). Since the biosphere preferentially takes the light ${ }^{12} \mathrm{C}$ over ${ }^{13} \mathrm{C}$ during photosynthesis, the atmosphere becomes enriched in ${ }^{13} \mathrm{C}$ and $\delta^{13} \mathrm{C}_{\mathrm{atm}}$ increases (Fig. 11a). Yet, this trend disagrees with the data showing a " $W$ " shape, suggesting a more complex evolution of mechanisms.

Even when taking carbonate compensation into account, the computed $\mathrm{CO}_{2}$, atmospheric and deep oceanic $\delta^{13} \mathrm{C}$ evolutions are far from reproducing the evolution depicted by the data, underlining the need for additional mechanisms to explain the carbon cycle evolution. In the following, we test the three additional oceanic mechanisms described before during the deglaciation and assess their impact on the carbon cycle evolution when the global climate warms. 

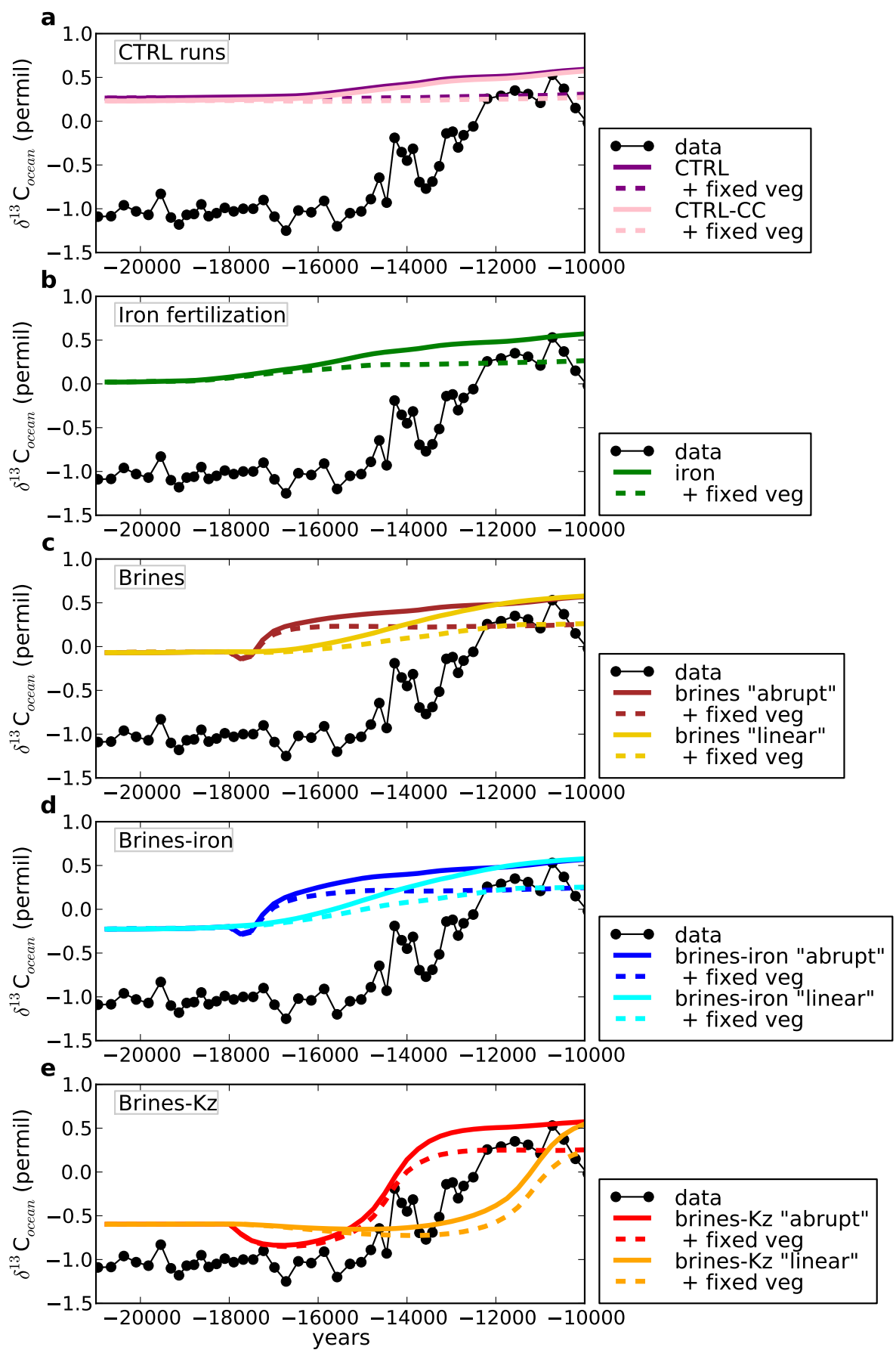

Fig. 10. Evolution of deep Southern Ocean $\delta^{13} \mathrm{C}$ during the last deglaciation with different oceanic mechanisms and comparison with data: (a) control (CTRL) runs without and with carbonate compensation (CC), all other simulations are with carbonate compensation, (b) simulations with iron fertilization, (c) simulations with the sinking of brines (two scenarios as defined in Fig. 6), (d) simulations with the sinking of brines (two scenarios as defined in Fig. 6) and iron fertilization, (e) simulations with the sinking of brines (two scenarios as defined in Fig. 6) and interactive vertical diffusion coefficient $\left(K_{z}\right)$. Each simulation has either an interactive vegetation or a fixed glacial vegetation ("fixed veg"). The data are from Waelbroeck et al. (2011). 

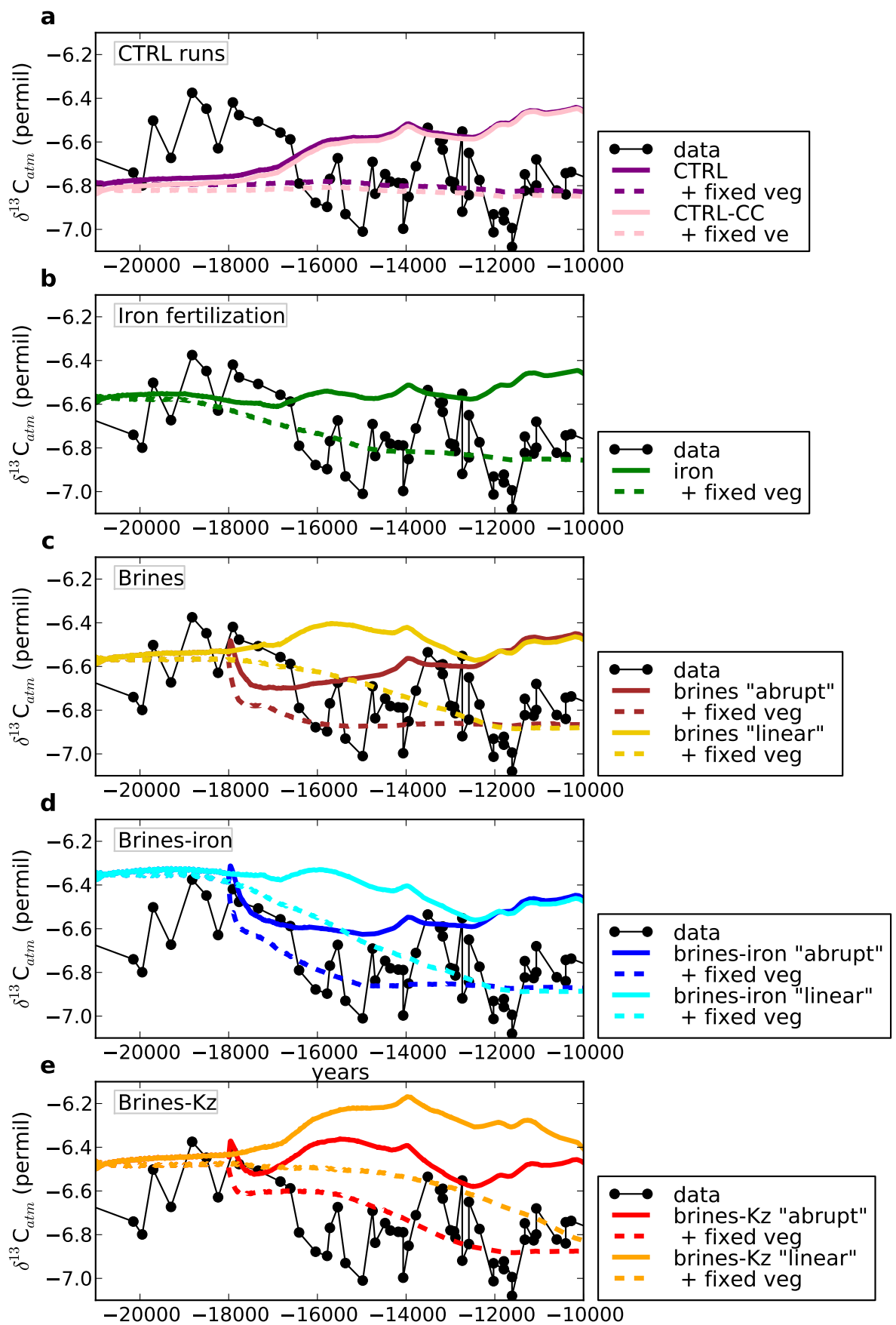

Fig. 11. Evolution of atmospheric $\delta^{13} \mathrm{C}_{\mathrm{atm}}$ during the last deglaciation with different oceanic mechanisms and comparison with data: (a) control (CTRL) runs without and with carbonate compensation (CC), all other simulations are with carbonate compensation, (b) simulations with iron fertilization, (c) simulations with the sinking of brines (two scenarios as defined in Fig. 6), (d) simulations with the sinking of brines (two scenarios as defined in Fig. 6) and iron fertilization, (e) simulations with the sinking of brines (two scenarios as defined in Fig. 6) and interactive vertical diffusion coefficient $\left(K_{z}\right)$. Each simulation has either an interactive vegetation or a fixed glacial vegetation ("fixed veg"). The data are from Lourantou et al. (2010). 


\subsubsection{Impact of iron fertilization}

The simulated atmospheric $\mathrm{CO}_{2}$ evolution improves when including the iron fertilization mechanism and rises from $\sim 230 \mathrm{ppm}$ at -21000 years to $\sim 260 \mathrm{ppm}$ at -10000 years (Fig. 8b). As the idealized experiment with a fixed climate has shown, the iron fertilization reacts quickly to the imposed forcing and the response thus follows the iron availability. The amplitude of the $\mathrm{CO}_{2}$ change due to iron fertilization is probably over-estimated in this simulation as a state-of-theart GCM including an iron cycle indicates a more probable modern to $\mathrm{LGM} \mathrm{CO}_{2}$ decline of $15-20 \mathrm{ppm}$ due to iron fertilization (Bopp et al., 2003; Tagliabue et al., 2009).

The computed LGM deep ocean $\delta^{13} \mathrm{C}$ evolution also improves (Fig. 10b), yet its amplitude is clearly not large enough (the glacial value is $\sim 0 \%$ compared to $\sim-1 \%$ in the data). The $\delta^{13} \mathrm{C}_{\mathrm{atm}}$ evolution changes as well (Fig. 11b). The initial glacial value is increased by $0.2 \%$ compared to the control simulation. Following the evolution of iron flux, iron fertilization decreases during the deglaciation. Similarly to the terrestrial biosphere, marine biology preferentially uses ${ }^{12} \mathrm{C}$ over ${ }^{13} \mathrm{C}$, which decreases $\delta^{13} \mathrm{C}$ in the deep ocean and increases it in the upper ocean and atmosphere. When iron fertilization becomes lower, the biological pump decreases and the deep ocean ocean $\delta^{13} \mathrm{C}$ increases while $\delta^{13} \mathrm{C}_{\mathrm{atm}}$ decreases. In the atmosphere, because this effect is of the same amplitude as the effect of the terrestrial biosphere, but with an opposite signe, the overall simulated evolution of $\delta^{13} \mathrm{C}_{\mathrm{atm}}$ is flat.

\subsubsection{Impact of the sinking of brines}

Taking into account the halt of the sinking of brines improves the computed $\mathrm{CO}_{2}$ evolution (Fig. 8c). Atmospheric $\mathrm{CO}_{2}$ increases from $\sim 220 \mathrm{ppm}$ at -21000 years to $\sim 260 \mathrm{ppm}$ at -10000 years. The transition is however different for the two brine scenarios. When the sinking of brines is suddenly stopped (referred as "abrupt" in the figure captions) the $\mathrm{CO}_{2}$ rapidly increases. The degassing due to the break down of the stratification and reorganisation of the thermohaline circulation (Fig. 12) takes approximately 3000 years to reach the level of the control evolution. The linear reduction of the sinking of brines ("linear") globally follows the forcing, which results in a smoother increase of atmospheric $\mathrm{CO}_{2}$. Yet, although the $\mathrm{CO}_{2}$ evolution is slightly closer to the data when including the sinking of brines than with iron fertilization, none of them alone can account for the entire $\mathrm{CO}_{2}$ rise during the deglaciation (Fig. 8), which is mainly due to the mismatch of the initial states compared to the data.

The evolution of the deep ocean $\delta^{13} \mathrm{C}$ is improved compared to the control simulations (Fig. 10c) as the initial LGM $\delta^{13} \mathrm{C}_{\text {ocean }}$ value is closer to the data (the simulated $\delta^{13} \mathrm{C}_{\text {ocean }}$ is $\sim 0 \%$ compared to $\sim 0.3 \%$ in the control simulations and $\sim-1 \%$ in the data). It is nonetheless still too high compared to the data.
The sinking of brines has a more striking impact on $\delta^{13} \mathrm{C}_{\text {atm }}$ (Fig. 11c). The abrupt halt of the sinking of brines at -18000 years leads to a decrease of $\delta^{13} \mathrm{C}_{\mathrm{atm}}$ as the carbon from the deep ocean characterized by low $\delta^{13} \mathrm{C}$ is released to the atmosphere. The decrease is larger when the vegetation is fixed because it only accounts for the oceanic change while in the simulation with interactive vegetation the increase of terrestrial biosphere carbon content (which increases $\delta^{13} \mathrm{C}_{\mathrm{atm}}$ ) counteracts the oceanic effect. When the halt of the sinking of brines is more progressive, the change of $\delta^{13} \mathrm{C}_{\mathrm{atm}}$ due to the ocean takes place later so that when the vegetation is interactive, the change due to the vegetation cancels out the one from the ocean and no decrease is simulated.

\subsubsection{Impact of the sinking of brines and iron fertilization}

With both the sinking of brines and iron fertilization included in the model, the entire amplitude of the $\mathrm{CO}_{2}$ rise from $\sim 190$ ppm at -21000 years to $\sim 260$ ppm at -10000 years is simulated (Fig. 8d). The "abrupt" scenario leads to an early increase of $\mathrm{CO}_{2}$, which begins in advance compared to the data (around 1000 years in advance). The "linear" scenario is more similar to the data evolution. The separate effects of the sinking of brines and iron fertilization globally reinforce each other. Indeed, the sinking of brines alters the ocean dynamics while iron fertilization changes the marine biology. The sinking of brines induces a slight reduction of the surface nutrient concentration, hence a diminished effect of iron fertilization, yet the impact on atmospheric $\mathrm{CO}_{2}$ is very small (a few ppm only). Thus, the two mechanisms are almost independent of each other and their effects linearly add to each other. This combined effect is responsible for the very steep increase of $\mathrm{CO}_{2}$ in the "abrupt" scenario as both mechanisms have a fast response of their own.

Yet, the evolution of $\delta^{13} \mathrm{C}_{\text {ocean }}$ is still relatively different from the data (Fig. 10d), with a decrease of $\sim 0.7 \%$ o compared to $\sim 1.3 \%$ in the data, mostly because of the mismatch between the initial value and the data. The sinking of brines has an important effect on $\delta^{13} \mathrm{C}_{\text {ocean }}$ but the iron fertilization has a very small effect and the addition of the two cannot account for the entire measured evolution during deglaciation.

The combination of the sinking of brines and iron fertilization yields better results for the $\delta^{13} \mathrm{C}_{\mathrm{atm}}$ evolution when the vegetation is fixed (Fig. 11d, dotted lines). In particular, between -18000 years and -15000 years the halt of the sinking of brines in addition to the diminishing iron fertilization produces a simulated $\delta^{13} \mathrm{C}_{\mathrm{atm}}$ decrease closer to the data. Yet when the vegetation is interactive (solid lines) this effect is counteracted by the increase of $\delta^{13} C_{\text {atm }}$ due to the expansion of the vegetation. 

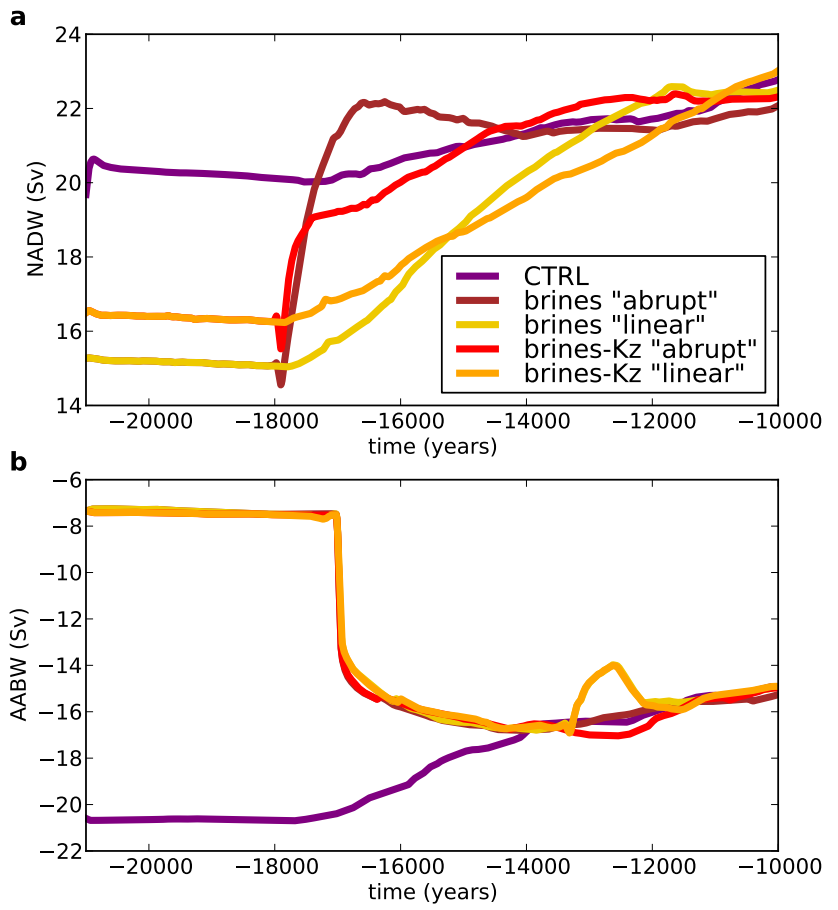

Fig. 12. Evolution of the thermohaline circulation during the deglaciation. (a) Evolution of the maximum value of the North Atlantic stream function (Sv) and (b) evolution of the maximum value of the Southern Ocean stream function (Sv).

\subsubsection{Impact of the sinking of brines and stratification-dependent diffusion}

With a combination of the sinking of brines and the stratification-dependent diffusion, the amplitude of the $\mathrm{CO}_{2}$ increase is also in line with the data (Fig. 8e). As observed with a constant climate forcing, the effect of the brine induced stratification is amplified, the deep water mass is further isolated and stores more carbon at the LGM. The interactive diffusion also generates a delay in the oceanic response to the breakdown of the stratification and $\mathrm{CO}_{2}$ is more progressively released. Hence the scenario that best agrees with the $\mathrm{CO}_{2}$ record is now the "abrupt" scenario whereas the "linear" scenario is delayed and rises too late.

Contrary to the simulation with the sinking of brines and iron fertilization, the computed deep ocean $\delta^{13} \mathrm{C}$ is significantly improved (Fig. 10e) and the amplitude of the increase closer to the data. The interactive diffusion also amplifies the impact of the brines on $\delta^{13} \mathrm{C}_{\text {ocean }}$, which is further decreased in the LGM and then increases to the Holocene value during the deglaciation. The scenario that best matches the data evolution is again the "abrupt" scenario, the "linear" scenario yielding too late a rising.

However, the simulated $\delta^{13} \mathrm{C}_{\mathrm{atm}}$ does not really improve (Fig. 11e). It appears that the maxima of the " $W$ " shape correspond to the values of the simulations with interactive vegetation while the minima are close to the values of the "fixed veg" simulations. Overall the $\delta^{13} \mathrm{C}_{\mathrm{atm}}$ record seems to oscillate between these two states, which could indicate a more complex evolution of the vegetation that a simple linear increase during the transition. The vegetation could begin to increase later that in the simulation, then decrease around $-13000-12000$ years and then increase again (Köhler et al., 2005a). It confirms that the evolution of the terrestrial biosphere has an important impact on $\delta^{13} \mathrm{C}_{\mathrm{atm}}$ (Lourantou et al., 2010) and should be studied in more details in the future.

It results that the $\mathrm{CO}_{2}$ evolution can be simulated in agreement with data either with the combination of brines and iron fertilisation or brines and interactive diffusion. However, the evolution of $\delta^{13} \mathrm{C}_{\text {ocean }}$ better match the data with the brine and interactive diffusion combination while the $\delta^{13} \mathrm{C}_{\mathrm{atm}}$ is slightly better with the brines and iron combination. In the following we thus take the three mechanisms simultaneously into account. Because the $\mathrm{CO}_{2}$ is simulated in agreement with data, we also change the version of the model to a fully carbon-climate coupled version. The simulations are thus not forced by a $\mathrm{CO}_{2}$ record anymore.

\subsection{Evolution of the mechanisms during the last deglaciation with interactive $\mathrm{CO}_{2}$}

Contrary to the previous section, here the climate and carbon models are fully coupled and atmospheric $\mathrm{CO}_{2}$ is no longer prescribed but interactively computed. Because of this change in the version of the model, it is required to simulate new initial glacial conditions. We first evaluate these new glacial equilibrium runs before exploring the evolution of the interactive carbon cycle during the deglaciation.

\subsubsection{Initial glacial conditions}

We first carry out two glacial equilibrium simulations with ("LGM-all") and without ("LGM-ctrl") the additional mechanisms studied. The runs start from previous glacial equilibrium runs (Bouttes et al., 2011) performed with prescribed $\mathrm{CO}_{2}$ values $(190 \mathrm{ppm})$ for the climate model. The values of the parameters for the additional mechanisms included in the "LGM-all" simulation are based on the results from ensemble simulations (Bouttes et al., 2011) ( $\mathrm{frac}=0.6$ for the sinking of brines, iron $=0.3$ for iron fertilization and alpha $=0.7$ for the stratification dependand diffusion). With these three additional mechanisms ("LGM-all"), the climate at the end of the 50000 year simulation is slightly colder compared to the standard glacial simulation $\left(0.3^{\circ} \mathrm{C}\right.$ colder $)$. The global air surface temperature during the LGM is $4{ }^{\circ} \mathrm{C}$ colder compared to the preindustrial. In the "LGM-ctrl" run, $\mathrm{CO}_{2}$ increases from $\sim 254 \mathrm{ppm}$ and equilibrates close to preindustrial level ( $284 \mathrm{ppm}$ ) (Fig. 13). The atmospheric $\mathrm{CO}_{2}$ level is higher than the $\mathrm{CO}_{2}$ prescribed due to the carbon-climate feedbacks. Indeed, higher $\mathrm{CO}_{2}$ leads to higher temperature, which mainly reduces ocean solubility and further increases 


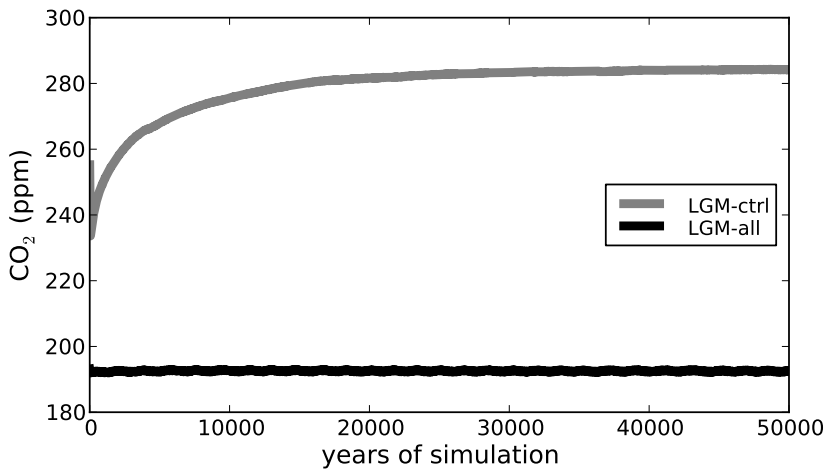

Fig. 13. Equilibrium simulations with LGM boundary conditions (LGM ice sheets and orbital parameters) with carbonate compensation ("LGM-ctrl") and with the combination of the three additional mechanisms ("LGM-all", sinking of brines, interactive diffusion and iron fertilization).

atmospheric $\mathrm{CO}_{2}$ until it equilibrates. On the contrary, the "LGM-all" run is stable and the simulated $\mathrm{CO}_{2}$ remains at the glacial level of $\sim 190 \mathrm{ppm}$. Because of the deep stratification induced by the sinking of brines, the interactive diffusion and the iron fertilization, the deep ocean contains more carbon, hence the relatively low simulated $\mathrm{CO}_{2}$. Based on these mechanisms, because atmospheric $\mathrm{CO}_{2}$ is now interactive, it is possible to study the temporal evolution of $\mathrm{CO}_{2}$ during the deglaciation. Indeed, the ends of these equilibrium runs constitute the initial conditions for the deglacial runs.

\subsubsection{Evolution of $\mathrm{CO}_{2}$ and $\delta^{13} \mathrm{C}$ during the last deglaciation with a combination of mechanisms}

As done previously, the ice sheet, sea level and insolation evolutions are prescribed. However, atmospheric $\mathrm{CO}_{2}$ is no longer prescribed. The $\mathrm{CO}_{2}$ concentration used to compute the radiative scheme comes from the $\mathrm{CO}_{2}$ calculated in the carbon cycle module. The evolution of iron fertilization is again prescribed following iron flux data and different scenarios are applied to the brine mechanism (Fig. 14a). The two scenarios explored before (linear decline "linear" and the sudden halt at $18 \mathrm{ky} \mathrm{BP} \mathrm{"abrupt")} \mathrm{are} \mathrm{again} \mathrm{considered,} \mathrm{and}$ we also study two additional ones: a sudden halt of the sinking of brines at $17 \mathrm{ky} \mathrm{BP}$ "abrupt $17 \mathrm{k}$ " and an intermediate one "intermediate".

In the control transient simulation ("CTRL"), atmospheric $\mathrm{CO}_{2}$ roughly stays around $280 \mathrm{ppm}$ (Fig. 14b). This evolution is due to the terrestrial biosphere, whose carbon content increase lowers atmospheric $\mathrm{CO}_{2}$. It counteracts the atmospheric $\mathrm{CO}_{2}$ increase due to the rising temperatures causing lower solubility. This evolution widely differs from the data, i.e. a general increase from the glacial level of $\sim 190 \mathrm{ppm}$ until the Holocene value of $\sim 260 \mathrm{ppm}$.

We then consider a combination of the three additional oceanic mechanisms during the deglaciation. With the

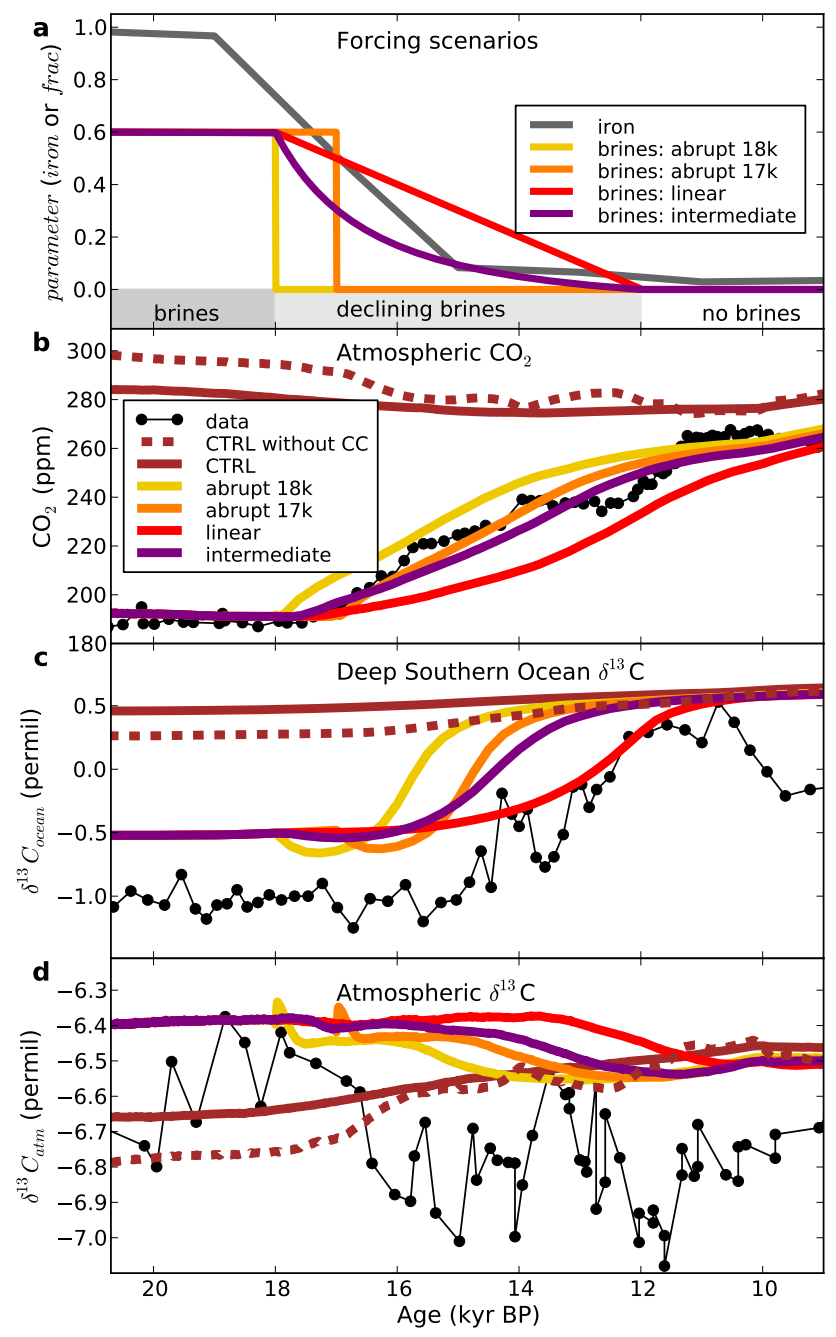

Fig. 14. Forcing scenarios and simulated evolution of atmospheric $\mathrm{CO}_{2}$, deep Southern Ocean $\delta^{13} \mathrm{C}$ and atmospheric $\delta^{13} \mathrm{C}$ during the deglaciation. (a) Evolution scenarios for the iron fertilization (iron parameter, grey) based on the dust transport as recorded in ice cores (Wolff et al., 2006) on the EDC3 age model (Parrenin et al., 2007), and sinking of brines (frac parameter, colors), (b) simulated evolution of atmospheric $\mathrm{CO}_{2}$ (ppm) for the control run ("CTRL" in brown, without carbonate compensation: dotted line and with carbonate compensation: solid line) and with three additional mechanisms: interactive diffusion, iron fertilization and different brine scenarios as described in (a) compared to data (black), (c) evolution of deep Southern Ocean $\delta^{13} \mathrm{C}(\% o$ ) for the same simulations and (d) of atmospheric $\delta^{13} \mathrm{C}(\%)$.

combination of iron fertilization, sinking of brines and stratification dependent diffusion, the obtained computed transitions are mainly driven by the ocean and match the global data evolution of $\mathrm{CO}_{2}$ better than the control simulation (Fig. 14b). The scenarios that best match the data are the "abrupt $17 \mathrm{k}$ " and "intermediate" ones that support a relatively rapid halt of the sinking of brines when the Antarctic ice sheet is at its maximum extent. In these runs, the 
simulated deep Southern Ocean $\delta^{13} \mathrm{C}$ transition is also improved, with an increase of $\sim 1 \%$ o beginning at $15.5 \mathrm{kyr} \mathrm{BP}$ (Fig. 14c). However, if the general trend is captured by the model, the $\mathrm{CO}_{2}$ plateau during the Bølling-Allerød (from $\sim 14 \mathrm{kyr} \mathrm{BP}$ to $\sim 12 \mathrm{kyr} \mathrm{BP}$ ) is not well represented, underlining the lack of other processes such as abrupt AMOC variations that were not considered in this study.

This global behaviour for $\mathrm{CO}_{2}$ and deep ocean $\delta^{13} \mathrm{C}$ during the termination is due to the modification of the ocean dynamics and reduced iron fertilization. The halt of the sinking of brines results in modifications of the overturning rate during the transition while iron fertilization induces changes in the biological production. During the glacial period, because of the sinking of brines, both the simulated North Atlantic Deep Water (NADW) and the Antarctic Bottom Water (AABW) export rates are weaker so that the deep water enriched in carbon is less mixed with the above water containing less carbon. As previously studied (Bouttes et al., 2010, 2011) the deep isolated water then represents an important carbon reservoir. The sinking of brines is responsible for a glacial $\mathrm{CO}_{2}$ change of $39 \mathrm{ppm}$ and the interactive diffusion scheme amplifies it by $16 \mathrm{ppm}$. During the transition the carbon trapped in the abyss is progressively released into the atmosphere because of the halt of the brines sink and break down of the stratification (Fig. 15). In addition, the decrease in iron fertilization, which accounts for $10 \mathrm{ppm}$ of the $\mathrm{LGM} \mathrm{CO}_{2}$ change, leads to a reduced biological production and therefore to a less effective biological pump. Similarly, the evolution of deep ocean $\delta^{13} \mathrm{C}$ is governed by the increasing mixing between surface water with high values of $\delta^{13} \mathrm{C}_{\text {ocean }}$ and deep water with low values of $\delta^{13} \mathrm{C}_{\text {ocean }}$. Because of the change of oceanic circulation the deep values increase and the vertical gradient is diminished. Although the general trend of the ocean $\delta^{13} \mathrm{C}$ evolution is well simulated with the model, the absolute values are slightly different. Because CLIMBER-2 is an intermediate complexity model with a low resolution and zonally averaged ocean, it complicates the comparison with the sediment core data. Similar experiments exploring the impacts of the sinking of brines with a better resolved 3-D ocean model should lead to a better comparison.

Although the amplitude of the glacial-interglacial Antarctic temperature change is underestimated in the model, it is possible to analyse the relative timing of $\mathrm{CO}_{2}$ and temperature evolution (Fig. 16). The two scenarios that agree best with $\mathrm{CO}_{2}$ and $\delta^{13} \mathrm{C}$ data ("abrupt $17 \mathrm{k}$ " and "intermediate") result in a lead of temperature relative to $\mathrm{CO}_{2}$ as inferred from termination 3 data (Caillon et al., 2003). The halt of the sinking of brines not only breaks down the stratification, which increases $\mathrm{CO}_{2}$ and therefore temperature, but also induces a decrease in sea ice formation (which is computed by a thermodynamic sea ice model) as the surface waters become saltier and warmer. Such an early deglacial retreat of sea ice is also indicated in the data (Shemesh et al., 2002). Because of the reduced albedo, temperature then increases,
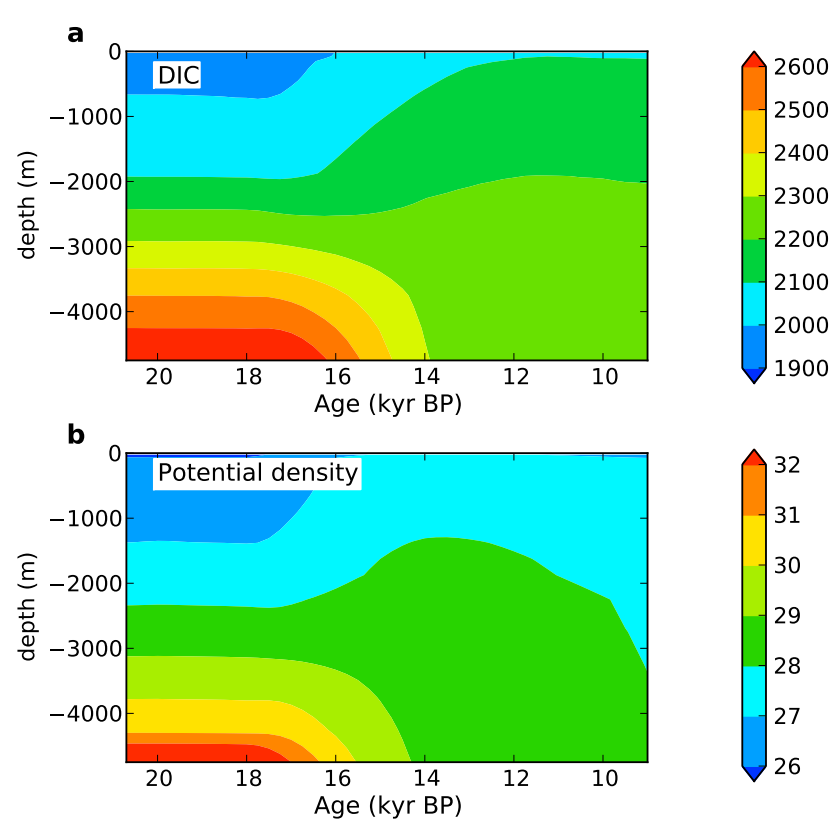

Fig. 15. Evolution of (a) Dissolved Inorganic Carbon (DIC, $\left.\mu \mathrm{mol} \mathrm{kg}{ }^{-1}\right)$ and (b) potential density anomaly $\left(\rho_{\theta}-1000 \mathrm{~kg} \mathrm{~m}^{-3}\right)$ as a function of depth at latitude $50^{\circ} \mathrm{S}$ of the Atlantic ocean sector.

resulting in a positive feedback. Antarctic temperature thus reacts quicker than $\mathrm{CO}_{2}$ at the beginning of the termination, despite the same unique triggering, i.e. the halt of stratification due to brines sinking.

Recently, two papers studied the evolution of the carbon cycle in the context of glacial-interglacial cycles. Tschumi et al. (2011) run transient simulations testing the sensitivity of various mechanisms in a constant climate. The simulations support the hypothesis that a change in the ventilation of the deep ocean played an important role in the variation of $\mathrm{CO}_{2}$ during glacial interglacial cycles. In this study, the change of deep ocean ventilation was obtained by changing the windstress whereas in our study the change of deep ocean stratification results from changing the sinking of brines. Our study also supports the important role of the change of deep ocean stratification. Furthermore, it demonstrates that it allows us to simulate the evolution of $\mathrm{CO}_{2}$ during the last deglaciation in agreement with $\mathrm{CO}_{2}$ and $\delta^{13} \mathrm{C}$ data without prescribing $\mathrm{CO}_{2}$. In particular, the interactive carbon-climate simulation manages to capture not only the right $\mathrm{CO}_{2}$ amplitude change, but also the right timing. With other mechanisms, Brovkin et al. (2011) run a full glacial-interglacial evolution of $\mathrm{CO}_{2}$ and northern ice sheets. In this simulation the role of the carbonate compensation due to changes in the weathering rate is important. However, although most of the $\mathrm{CO}_{2}$ evolution is successfully simulated, the timing of the $\mathrm{CO}_{2}$ rise during the deglaciation lags the data indicating that a mechanism leading to an earlier $\mathrm{CO}_{2}$ change is missing. With the change of deep stratification from the change 

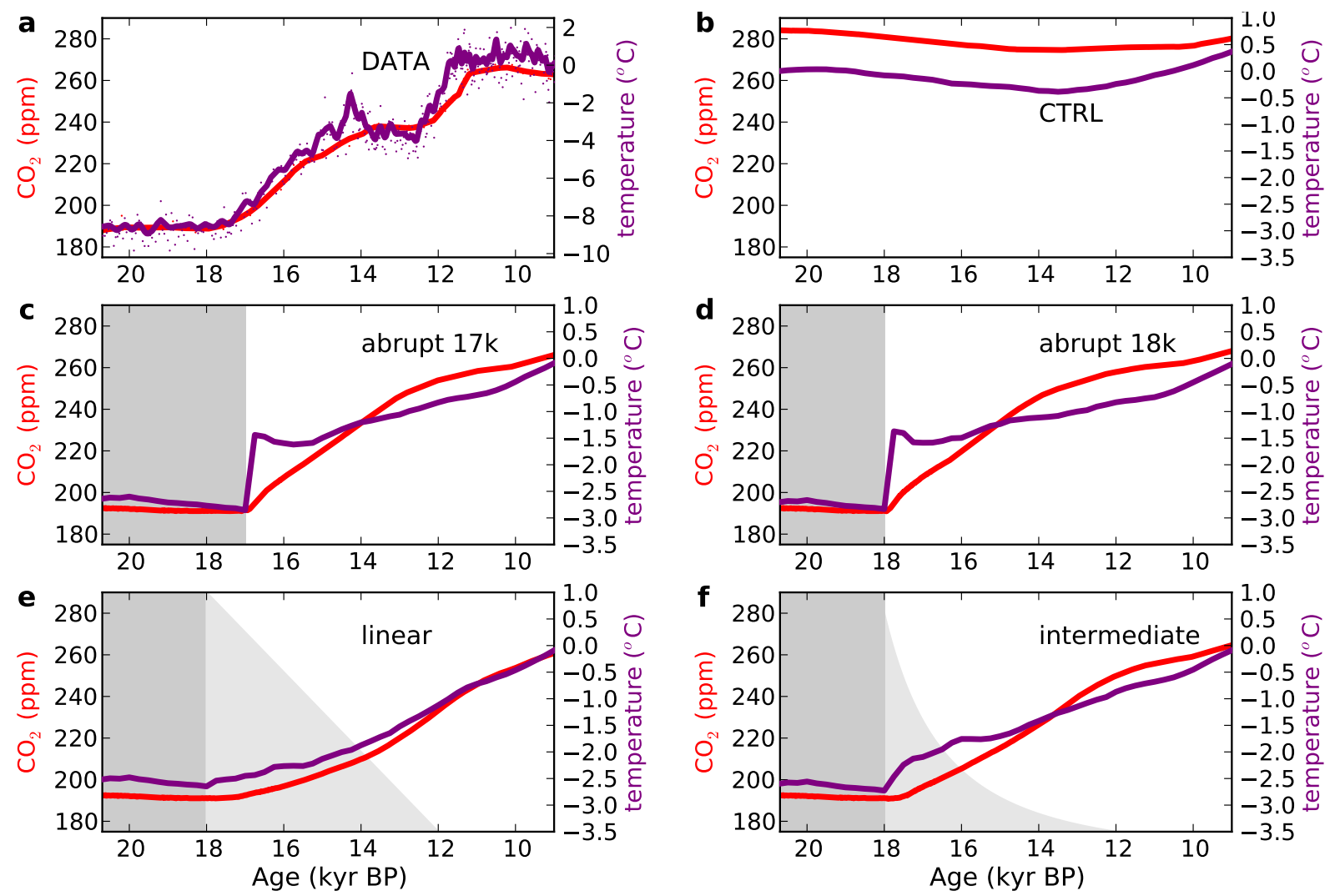

Fig. 16. Evolution of $\mathrm{CO}_{2}(\mathrm{ppm})$ and Antarctic temperature $\left({ }^{\circ} \mathrm{C}\right)$ during the deglaciations for (a) the data (Monnin et al., 2001; Lourantou et al., 2010; Jouzel et al., 2007), (b) the CTRL simulation (with carbonate compensation), (c, d, e, f) the simulations with interactive diffusion, iron fertilization and different brines scenarios as defined in Fig. 14a. The grey shading indicates the evolution of the sinking of brines according to each scenario.

of sinking of brines, it allows us to get this timing right, although it relies on scenarios that need to be comfirmed.

\section{Conclusions}

To summarize, we use the intermediate complexity model CLIMBER-2 to explore the impact of three oceanic mechanisms on the evolution of the carbon cycle during the last deglaciation: iron fertilization, sinking of brines and stratification-dependent diffusion. The carbonate compensation mechanism is included in the CLIMBER-2 model, which has already been used to study the LGM carbon cycle (Brovkin et al., 2002b, 2007; Bouttes et al., 2009, 2010, 2011).

A first set of simulations in a context of a constant LGM climate has allowed an evaluation of the effect of each mechanism separately. The iron fertilization of marine biology induces the fastest response of the carbon cycle $(\sim 100$ years) with a rapid increase in atmospheric $\mathrm{CO}_{2}$ of $\sim 29 \mathrm{ppm}$. The $\mathrm{CO}_{2}$ rise due to the sinking of brines $(\sim 40 \mathrm{ppm})$ takes longer (almost 1000 years) as it involves the oceanic circulation which takes more time to equilibrate than the marine biology. The combination of interactive diffusion with the sinking of brines induces an important delay as the vertical diffusion has to adjust to the evolving circulation. The carbon cycle then takes $\sim 4000$ years to equilibrate. The impact of iron fertilization on $\delta^{13} \mathrm{C}_{\text {ocean }}$ is small $(-0.12 \%$ ). It is important for $\delta^{13} \mathrm{C}_{\mathrm{atm}}(-0.25 \%$ ). The effect of the sinking of brines is important on both deep ocean $\delta^{13} \mathrm{C}(-0.57 \%$ ) and $\delta^{13} \mathrm{C}_{\mathrm{atm}}(-0.25 \%$ ). Adding the stratification-dependent diffusion amplifies the effect of the sinking of brines on $\mathrm{CO}_{2}$ (61 ppm), deep ocean $\delta^{13} \mathrm{C}\left(-1.1 \%\right.$ ) and $\delta^{13} \mathrm{C}_{\mathrm{atm}}(-0.34 \%$ ) due to the decrease in mixing between the deep and upper waters, which makes the deep water enriched in carbon and depleted in $\delta^{13} \mathrm{C}$ even more isolated with more carbon and lower $\delta^{13} \mathrm{C}$.

With the varying climate of the last termination, the impact of the evolution of these mechanisms is modulated by other changes such as the warming and increase in the terrestrial biosphere carbon content. In this context, either the association of the sinking of brines with iron fertilization or with interactive diffusion results in a computed atmospheric $\mathrm{CO}_{2}$ increase in agreement with the data. However, only the 
combination of brines with interactive diffusion also reconciles the simulated $\delta^{13} \mathrm{C}_{\text {ocean }}$ with the recorded $\delta^{13} \mathrm{C}$ evolution in the deep Southern Ocean. In the latter case, the scenario that best matches the data is the "abrupt" scenario, i.e. a sudden halt of the sinking of brines when the Antarctic ice sheet is at its maximum extent. In such a configuration, sea ice formation is shifted to the open ocean instead of the shelf. The dense water from brine rejection is then mixed with fresher water preventing it from sinking down to the abyss.

Based on the study of these mechanisms during the deglaciation and previous studies of the possible combinations of the mechanisms in glacial conditions (Bouttes et al., 2011), it is possible to use the model in an fully interactive carbon-climate version. The simulated evolution of $\mathrm{CO}_{2}$ is in good agreement with the data underlining the powerful impact of the combination of the sinking of brines, stratification dependent diffusion and iron fertilization.

Although the computed $\mathrm{CO}_{2}$ and deep ocean $\delta^{13} \mathrm{C}$ are in broad agreement with proxy data, the computed $\delta^{13} \mathrm{C}_{\mathrm{atm}}$ presents important discrepancies with respect to the data both in magnitude and structure. The persisting mismatch between model results and data for $\delta^{13} \mathrm{C}_{\mathrm{atm}}$ points to the role of vegetation, which could modulate the $\delta^{13} \mathrm{C}_{\mathrm{atm}}$ signal inducing low values when the vegetation is reduced and high values when the vegetation is increased. The change in the terrestrial biosphere seems to play a less important role for $\mathrm{CO}_{2}$ and deep ocean $\delta^{13} \mathrm{C}$, which are mostly driven by oceanic mechanisms. This source discrimination between atmospheric mixing and isotopic $\mathrm{CO}_{2}$ ratios has been recently explored (Lourantou et al., 2010). $\delta^{13} \mathrm{C}_{\mathrm{atm}}$ data can thus help to constrain the vegetation evolution which is poorly known.

The $\delta^{13} \mathrm{C}_{\mathrm{atm}}$ mismatch can also point to the potential role of abrupt events, which were not considered in this study. Additionally, the lack of abrupt events is underlined by the absence of the $\mathrm{CO}_{2}$ plateau during the Bolling-Allerod, as this plateau could also be linked to abrupt events associated to fresh water fluxes (Stocker and Wright, 1991). Indeed, fresh water fluxes, which can alter the thermohaline circulation, have an impact on the carbon cycle (Schmittner and Galbraith, 2008; Köhler et al., 2005b; Menviel et al., 2008b). Taking them into account could possibly improve both the $\mathrm{CO}_{2}$ plateau and the $\delta^{13} \mathrm{C}_{\mathrm{atm}}$ evolution.

Acknowledgements. We thank Victor Brovkin, Andrey Ganopolski, Guy Munhoven and Emilie Capron for useful comments and discussion. We also thank the editor and two anonymous reviewers for their comments which helped improve this manuscript.

Edited by: M. Siddall

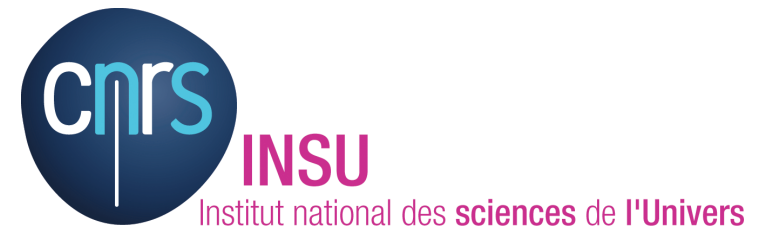

The publication of this article is financed by CNRS-INSU.

\section{References}

Anderson, J. B., Shipp, S. S., Lowe, A. L., Wellner, J. S., and Mosola, A. B.: The Antarctic Ice Sheet during the Last Glacial Maximum and its subsequent retreat history: a review, Quaternary Sci. Rev., 21, 49-70, doi:10.1016/S0277-3791(01)00083-X, 2002.

Archer, D.: Modeling the Calcite Lysocline, J. Geophys. Res., 96, 17037-17050, 1991.

Archer, D., Winguth, A., Lea, D., and Mahowald, N.: What caused the glacial/interglacial $p \mathrm{CO}_{2}$ cycles?, Rev. Geophys., 38, 159$189,2000$.

Archer, D. E., Martin, P. A., Milovich, J., Brovkin, V., Plattner, G.K., and Ashendel, C.: Model sensitivity in the effect of Antarctic sea ice and stratification on atmospheric $p \mathrm{CO}_{2}$, Paleoceanography, 18, 1012, doi:10.1029/2002PA000760, 2003.

Barker, S., Diz, P., Vautravers, M. J., Pike, J., Knorr, G., Hall, I. R., and Broecker, W. S.: Interhemispheric Atlantic seesaw response during the last deglaciation, Nature, 457, 1097-1102, doi:10.1038/nature07770, 2009.

Berger, A., Loutre, M. F., and Gallée, H.: Sensitivity of the LLN climate model to the astronomical and $\mathrm{CO}_{2}$ forcings over the last $200 \mathrm{ky}$, Clim. Dynam., 14, 615-629, doi:10.1007/s003820050245, 1998.

Berger, A. L.: Long-term variations of daily insolation and Quaternary climatic changes, J. Atmos. Sci., 35, 2362-2368, 1978.

Berger, W. H.: Increase of carbon dioxide in the atmosphere during Deglaciation: the coral reef hypothesis, Naturwissenschaften, 69, 87-88, 1982.

Bird, M. I., Lloyd, J., and Farquhar, G. D.: Terrestrial carbon storage at the LGM, Nature, 371, 566, 1994.

Bopp, L., Kohfeld, K. E., Quéré, C. L., and Aumont, O.: Dust impact on marine biota and atmospheric $\mathrm{CO}_{2}$ during glacial periods, Paleoceanography, 18, 1046, doi:10.1029/2002PA000810, 2003.

Bouttes, N., Roche, D. M., and Paillard, D.: Impact of strong deep ocean stratification on the carbon cycle, Paleoceanography, 24, PA3203, doi:10.1029/2008PA001707, 2009.

Bouttes, N., Paillard, D., and Roche, D. M.: Impact of brineinduced stratification on the glacial carbon cycle, Clim. Past, 6, 575-589, doi:10.5194/cp-6-575-2010, 2010.

Bouttes, N., Paillard, D., Roche, D. M., Brovkin, V., and Bopp, L.: Last Glacial Maximum $\mathrm{CO}_{2}$ and $\delta^{13} \mathrm{C}$ successfully reconciled, Geophys. Res. Lett., 38, L02705, doi:10.1029/2010GL044499, 2011.

Broecker, W. S. and Peng, T.-H.: Tracers in the Sea, LamontDoherty Geological Observatory of Columbia University, Palisades, New York, 1982. 
Broecker, W. S. and Peng, T.-H.: The Role of $\mathrm{CaCO}_{3}$ Compensation in the Glacial to Interglacial Atmospheric $\mathrm{CO}_{2}$ Change, Global Biogeochem. Cy., 1, 15-29, 1987.

Brovkin, V., Bendtsen, J., Claussen, M., Ganopolski, A., Kubatzki, C., Petoukhov, V., and Andreev, A.: Carbon cycle, vegetation, and climate dynamics in the Holocene: Experiments with the CLIMBER-2 model, Global Biogeochem. Cy., 16, 1139, doi:10.1029/2001GB001662, 2002a.

Brovkin, V., Hofmann, M., Bendtsen, J., and Ganopolski, A.: Ocean biology could control atmospheric $\delta^{13} \mathrm{C}$ during glacialinterglacial cycle, Geochem. Geophys. Geosyst., 3, 1027, doi:10.1029/2001GC000270, 2002b.

Brovkin, V., Ganopolski, A., Archer, D., and Rahmstorf, S.: Lowering of glacial atmospheric $\mathrm{CO}_{2}$ in response to changes in oceanic circulation and marine biogeochemistry, Paleoceanography, 22, PA4202, doi:10.1029/2006PA001380, 2007.

Brovkin, V., Ganopolski, A., Archer, D., and Munhoven, G.: Glacial $\mathrm{CO}_{2}$ cycle as a succession of key physical and biogeochemical processes, Clim. Past Discuss., 7, 1767-1795, doi:10.5194/cpd-7-1767-2011, 2011.

Caillon, N., Severinghaus, J. P., Jouzel, J., Barnola, J.-M., Kang, J., and Lipenkov, V. Y.: Timing of Atmospheric $\mathrm{CO}_{2}$ and Antarctic Temperature Changes Across Termination III, Science, 299, 1728, doi:10.1126/science.1078758, 2003.

Charbit, S., Kageyama, M., Roche, D., Ritz, C., and Ramstein, G.: Investigating the mechanisms leading to the deglaciation of past continental northern hemisphere ice sheets with the CLIMBER GREMLINS coupled model, Global Planet. Change, 48, 253-273, doi:10.1016/j.gloplacha.2005.01.002, 2005.

Clark, P. U., Dyke, A. S., Shakun, J. D., Carlson, A. E., Clark, J., Wohlfarth, B., Mitrovica, J. X., Hostetler, S. W., and McCabe, A. M.: The Last Glacial Maximum, Science, 325, 710 714, doi:10.1126/science.1172873, 2009.

Crowley, T.: Ice Age Terrestrial Carbon Changes Revisited, Global Biogeochem. Cy., 9, 377-389, 1995.

Cuffey, K. M. and Vimeux, F.: Covariation of carbon dioxide and temperature from the Vostok ice core after deuterium-excess correction, Nature, 412, 523-527, doi:10.1038/35087544, 2001.

Curry, W. B. and Oppo, D. W.: Glacial water mass geometry and the distribution of $\delta^{13} \mathrm{C}$ of $\Sigma \mathrm{CO}_{2}$ in the western Atlantic Ocean, Paleoceanography, 20, PA1017, doi:10.1029/2004PA001021, 2005.

EPICA community members: Eight glacial cycles from an Antarctic ice core, Nature, 429, 623-628, 2004.

Fischer, H., Schmitt, J., Lüthi, D., Stocker, T. F., Tschumi, T., Parekh, P., Joos, F., Köhler, P., Völker, C., Gersonde, R., Barbante, C., Floch, M. L., Raynaud, D., and Wolff, E.: The role of Southern Ocean processes on orbital and millennial $\mathrm{CO}_{2}$ variations - a synthesis, Quaternary Sci. Rev., 29, 193-205, doi:10.1016/j.quascirev.2009.06.007, 2010.

Ganopolski, A. and Rahmstorf, S.: Rapid changes of glacial climate simulated in a coupled climate model, Nature, 409, 153158, 2001.

Ganopolski, A., Petoukhov, V., Rahmstorf, S., Brovkin, V., Claussen, M., Eliseev, A., and Kubatzki, C.: CLIMBER-2: A climate system model of intermediate complexity, part II: Model sensitivity, Clim. Dynam., 17, 735-751, 2001.
Ganopolski, A., Calov, R., and Claussen, M.: Simulation of the last glacial cycle with a coupled climate ice-sheet model of intermediate complexity, Clim. Past, 6, 229-244, doi:10.5194/cp-6-2292010, 2010.

Gersonde, R., Crosta, X., Abelmann, A., and Armand, L.: Seasurface temperature and sea ice distribution of the Southern Ocean at the EPILOG Last Glacial Maximum -a circumAntarctic view based on siliceous microfossil records, Quaternary Sci. Rev., 24, 869-896, 2005.

Hodell, D. A., Venz, K. A., Charles, C. D., and Ninnemann, U. S.: Pleistocene vertical carbon isotope and carbonate gradients in the South Atlantic sector of the Southern Ocean, Geochem. Geophy. Geosy., 4, 1-19, doi:10.1029/2002GC000367, 2003.

Huybrechts, P.: Sea-level changes at the LGM from ice-dynamic reconstructions of the Greenland and Antarctic ice sheets during the glacial cycles, Quaternary Sci. Rev., 21, 203-231, doi:10.1016/S0277-3791(01)00082-8, 2002.

Joos, F., Gerber, S., Prentice, I. C., Otto-Bliesner, B. L., and Valdes, P. J.: Transient simulations of Holocene atmospheric carbon dioxide and terrestrial carbon since the Last Glacial Maximum, Global Biogeochem. Cy., 18, GB2002, doi:10.1029/2003GB002156, 2004.

Jouzel, J., Masson-Delmotte, V., Cattani, O., Dreyfus, G., Falourd, S., Hoffmann, G., Minster, B., Nouet, J., Barnola, J. M., Chappellaz, J., Fischer, H., Gallet, J. C., Johnsen, S., Leuenberger, M., Loulergue, L., Luethi, D., Oerter, H., Parrenin, F., Raisbeck, G., Raynaud, D., Schilt, A., Schwander, J., Selmo, E., Souchez, R., Spahni, R., Stauffer, B., Steffensen, J. P., Stenni, B., Stocker, T. F., Tison, J. L., Werner, M., and Wolf, E. W.: Orbital and Millennial Antarctic Climate Variability over the Past 800,000 Years, Science, 317, 793, doi:10.1126/science.1141038, 2007.

Kaplan, J. O., Prentice, I. C., Knorr, W., and Valdes, P. J.: Modeling the dynamics of terrestrial carbon storage since the Last Glacial Maximum, Geophys. Res. Lett., 29, 2074, doi:10.1029/2002GL015230, 2002.

Keigwin, L. D., Jones, G. A., Lehman, S. J., and Boyle, E. A.: Deglacial Meltwater Discharge, North Atlantic Deep Circulation, and Abrupt Climate Change, J. Geophys. Res., 96, 1681116826, 1991.

Köhler, P. and Fischer, H.: Simulating changes in the terrestrial biosphere during the last glacial/interglacial transition, Global Planet. Change, 43, 33-55, doi:10.1016/j.gloplacha.2004.02.005, 2004.

Köhler, P., Fischer, H., Munhoven, G., and Zeebe, R. E.: Quantitative interpretation of atmospheric carbon records over the last glacial termination, Global Biogeochem. Cy., 19, GB4020, doi:10.1029/2004GB002345, 2005a.

Köhler, P., Joos, F., Gerber, S., and Knutti, R.: Simulated changes in vegetation distribution, land carbon storage, and atmospheric $\mathrm{CO}_{2}$ in response to a collapse of the North Atlantic thermohaline circulation, Clim. Dynam., 25, 689-708, doi:10.1007/s00382005-0058-8, 2005b.

Kohfeld, K. E., Quéré, C. L., Harrison, S. P., and Anderson, R. F.: Role of Marine Biology in Glacial-Interglacial $\mathrm{CO}_{2}$ Cycles, Science, 308, 74-78, 2005.

Lourantou, A., Lavric, J. V., Köhler, P., Barnola, J.-M., Paillard, D., Michel, E., Raynaud, D., and Chappellaz, J.: Constraint of the $\mathrm{CO}_{2}$ rise by new atmospheric carbon isotopic measurements during the last deglaciation, Global Biogeochem. Cy., 24, GB2015, 
doi:10.1029/2009GB003545, 2010.

Mackintosh, A., Golledge, N., Domack, E., Dunbar, R., Leventer, A., White, D., Pollard, D., DeConto, R., Fink, D., Zwartz, D., Gore, D., and Lavoie, C.: Retreat of the East Antarctic ice sheet during the last glacial termination, Nat. Geosci., 4, 195202, doi:10.1038/ngeo1061, 2011.

MARGO Project Members: Constraints on the magnitude and patterns of ocean cooling at the Last Glacial Maximum, Nat. Geosci., 2, 127-132, doi:10.1038/ngeo411, 2009.

Martin, J. H.: Glacial-Interglacial $\mathrm{CO}_{2}$ change: the iron hypothesis, Paleoceanography, 5, 1-13, 1990.

Marzeion, B., Levermann, A., and Mignot, J.: The Role of Stratification-Dependent Mixing for the Stability of the Atlantic Overturning in a Global Climate Model, J. Phys. Oceanogr., 37, 2672-2681, doi:10.1175/2007JPO3641.1, 2007.

Menviel, L., Timmermann, A., Mouchet, A., and Timm, O.: Climate and marine carbon cycle response to changes in the strength of the Southern Hemispheric westerlies, Paleoceanography, 23, PA4201, doi:10.1029/2008PA001604, 2008a.

Menviel, L., Timmermann, A., Mouchet, A., and Timm, O.: Meridional reorganizations of marine and terrestrial productivity during Heinrich events, Paleoceanography, 23, PA1203, doi:10.1029/2007PA001445, 2008b.

Monnin, E., Indermühle, A., Daellenbach, A., Flueckiger, J., Stauffer, B., Stocker, T. F., Raynaud, D., and Barnola, J.-M.: Atmospheric $\mathrm{CO}_{2}$ concentrations over the Last Glacial Termination, Science, 291, 112-114, 2001.

Montenegro, A., Eby, M., Kaplan, J. O., Meissner, J., and Weaver, A. J.: Carbon storage on exposed continental shelves during the glacial-interglacial transition, Geophys. Res. Lett., 33, L08703, doi:10.1029/2005GL025480, 2006.

North Greenland Ice Core Project members: High-resolution record of Northern Hemisphere climate extending into the last interglacial period, Nature, 431, 147-151, doi:10.1038/nature02805, 2004.

Opdyke, B. N. and Walker, J. C. G.: Return of the coral reef hypothesis: Basin to shelf partitioning of $\mathrm{CaCO}_{3}$ and its effect on atmospheric $\mathrm{CO}_{2}$, Geology, 20, 733-736, 1992.

Paillard, D. and Parrenin, F.: The Antarctic ice sheet and the triggering of deglaciations, Earth Planet. Sc. Lett., 227, 263-271, 2004.

Parrenin, F., Barnola, J.-M., Beer, J., Blunier, T., Castellano, E., Chappellaz, J., Dreyfus, G., Fischer, H., Fujita, S., Jouzel, J., Kawamura, K., Lemieux-Dudon, B., Loulergue, L., MassonDelmotte, V., Narcisi, B., Petit, J.-R., Raisbeck, G., Raynaud, D., Ruth, U., Schwander, J., Severi, M., Spahni, R., Steffensen, J. P., Svensson, A., Udisti, R., Waelbroeck, C., and Wolff, E.: The EDC3 chronology for the EPICA Dome C ice core, Clim. Past, 3, 485-497, doi:10.5194/cp-3-485-2007, 2007.

Peltier, W. R.: Ice age paleotopography, Science, 265, 195-201, doi:10.1126/science.265.5169.195, 1994.

Peltier, W. R.: Global glacial isostasy and the surface of the ice-age Earth: The ICE-5G (VM2) Model and GRACE, Ann. Rev. Earth Planet. Sci., 32, 111-149, doi:10.1146/annurev.earth.32.082503.144359, 2004.

Petoukhov, V., Ganopolski, A., Eliseev, A., Kubatzki, C., and Rahmstorf, S.: CLIMBER-2: A climate system model of intermediate complexity, part I: Model description and performance for present climate, Clim. Dynam., 16, 1-17, 2000.
Ritz, C., Rommelaere, V., and Dumas, C.: Modeling the evolution of Antarctic ice sheet over the last 420,000 years: Implications for altitude changes in the Vostok region, J. Geophys. Res., 106, 31943-31964, 2001.

Schmittner, A. and Galbraith, E. D.: Glacial greenhouse-gas fluctuations controlled by ocean circulation changes, Nature, 456, 373-376, doi:10.1038/nature07531, 2008.

Schneider von Deimling, T., Ganopolski, A., Held, H., and Rahmstorf, S.: How cold was the Last Glacial Maximum?, Geophys. Res. Lett., 33, L14709, doi:10.1029/2006GL026484, 2006.

Shemesh, A., Hodell, D., Crosta, X., Kanfoush, S., Charles, C., and Guilderson, T.: Sequence of events during the last deglaciation in Southern Ocean sediments and Antarctic ice cores, Paleoceanography, 17, 1056, doi:10.1029/2000PA000599, 2002.

Sigman, D. M. and Boyle, E. A.: Glacial/interglacial variations in atmospheric carbon dioxide, Nature, 407, 859-869, doi:10.1038/35038000, 2000.

Sigman, D. M., Hain, M. P., and Haug, G. H.: The polar ocean and glacial cycles in atmospheric $\mathrm{CO}_{2}$ concentration, Nature, 466, 47-55, doi:10.1038/nature09149, 2010.

Skinner, L. C., Fallon, S., Waelbroeck, C., Michel, E., and Barker, S.: Ventilation of the Deep Southern Ocean and Deglacial $\mathrm{CO}_{2}$ Rise, Science, 328, 1147-1151, doi:10.1126/science.1183627, 2010.

Stephens, B. B. and Keeling, R. F.: The influence of Antarctic sea ice on glacial-interglacial $\mathrm{CO}_{2}$ variations, Nature, 404, 171-174, 2000.

Stocker, T. F. and Wright, D.: Rapid transitions of the ocean's deep circulation induced by changes in the surface water fluxes, Nature, 351, 729-732, 1991.

Svendsen, J. I., Alexanderson, H., Astakhov, V. I., Demidov, I., Dowdeswell, J. A., Funder, S., Gataullin, V., Henriksen, M., Hjort, C., Houmark-Nielsen, M., Hubberten, H. W., Ingólfsson, Ó, Jakobsson, M., Kjær, K. H., Larsen, E., Lokrantz, H., Lunkka, J. P., Lyså, A., Mangerud, J., Matiouchkov, A., Murray, A., Möller, P., Niessen, F., Nikolskaya, O., Polyak, L., Saarnisto, M., Siegert, C., Siegert, M. J., Spielhagen, R. F., and Stein, R.: Late Quaternary ice sheet history of northern Eurasia, Quaternay Sci. Rev., 23, 1229-1271, doi:10.1016/j.quascirev.2003.12.008, 2004.

Tagliabue, A., Bopp, L., Roche, D. M., Bouttes, N., Dutay, J.-C., Alkama, R., Kageyama, M., Michel, E., and Paillard, D.: Quantifying the roles of ocean circulation and biogeochemistry in governing ocean carbon-13 and atmospheric carbon dioxide at the last glacial maximum, Clim. Past, 5, 695-706, doi:10.5194/cp5-695-2009, 2009.

Toggweiler, J. R.: Variation of atmospheric $\mathrm{CO}_{2}$ by ventilation of the ocean's deepest water, Paleoceanography, 14, 571-588, 1999.

Toggweiler, J. R., Russell, J. L., and Carson, S. R.: Midlatitude westerlies, atmospheric $\mathrm{CO}_{2}$, and climate change during the ice ages, Paleoceanography, 21, PA2005, doi:10.1029/2005PA001154, 2006.

Tschumi, T., Joos, F., Gehlen, M., and Heinze, C.: Deep ocean ventilation, carbon isotopes, marine sedimentation and the deglacial $\mathrm{CO}_{2}$ rise, Clim. Past, 7, 771-800, doi:10.5194/cp-7-771-2011, 2011. 
Visser, K., Thunell, R., and Stott, L.: Magnitude and timing of temperature change in the Indo-Pacific warm pool during deglaciation, Nature, 421, 152-155, doi:10.1038/nature01297, 2003.

Waelbroeck, C., Labeyrie, L., Michel, E., Duplessy, J. C., McManus, J. F., Lambeck, K., Balbon, E., and Labracherie, M.: Sea-level and deep water temperature changes derived from benthic foraminifera isotopic records, Quaternary Sci. Rev., 21, 295305, doi:10.1016/S0277-3791(01)00101-9, 2002.

Waelbroeck, C., Skinner, L. C., Labeyrie, L., Duplessy, J.-C., Michel, E., Riveiros, N. V., Gherardi, J.-M., and Dewilde, F.: The timing of deglacial circulation changes in the Atlantic, Paleoceanography, 26, PA3213, doi:10.1029/2010PA002007, 2011.
Watson, A. J. and Garabato, A. C. N.: The role of Southern Ocean mixing and upwelling in glacial-interglacial atmospheric $\mathrm{CO}_{2}$ change, Tellus B, 58, 73-87, doi:10.1111/j.16000889.2005.00167.x, 2005.

Wolff, E. W., Fischer, H., Fundel, F., Ruth, U., Twarloh, B., Littot, G. C., Mulvaney, R., Róthlisberger, R., de Angelis, M., Boutron, C. F., Hansson, M., Jonsell, U., Hutterli, M. A., Lambert, F., Kaufmann, P., Stauffer, B., Stocker, T. F., Steffensen, J. P., Bigler, M., Siggaard-Andersen, M. L., Udisti, R., Becagli, S., Castellano, E., Severi, M., Wagenbach, D., Barbante, C., Gabrielli, P., and Gaspari, V.: Southern Ocean sea-ice extent, productivity and iron flux over the past eight glacial cycles, Nature, 440, 491-496, doi:10.1038/nature04614, 2006. 